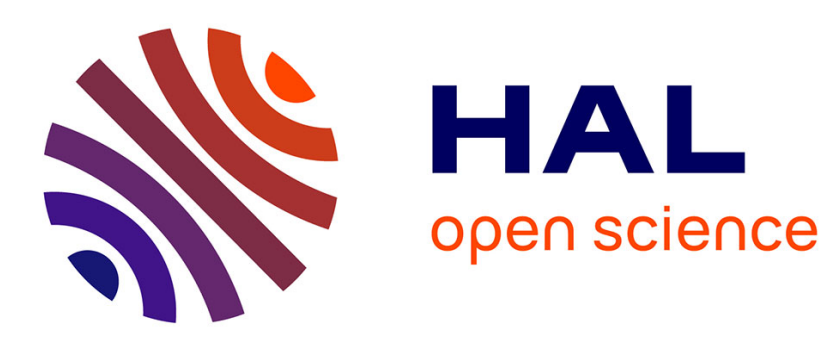

\title{
Analytical and numerical modeling of the bond behavior between FRP reinforcing bars and concrete
}

\author{
Arnaud Rolland, Pierre Argoul, Karim Benzarti, Marc Quiertant, Sylvain
}

Chataigner, Aghiad Khadour

\section{- To cite this version:}

Arnaud Rolland, Pierre Argoul, Karim Benzarti, Marc Quiertant, Sylvain Chataigner, et al.. Analytical and numerical modeling of the bond behavior between FRP reinforcing bars and concrete. Construction and Building Materials, 2020, 231, 14 p. 10.1016/j.conbuildmat.2019.117160 . hal02972515

\section{HAL Id: hal-02972515 \\ https://hal.science/hal-02972515}

Submitted on 7 Jun 2021

HAL is a multi-disciplinary open access archive for the deposit and dissemination of scientific research documents, whether they are published or not. The documents may come from teaching and research institutions in France or abroad, or from public or private research centers.
L'archive ouverte pluridisciplinaire HAL, est destinée au dépôt et à la diffusion de documents scientifiques de niveau recherche, publiés ou non, émanant des établissements d'enseignement et de recherche français ou étrangers, des laboratoires publics ou privés. 


\title{
Analytical and numerical modeling of the bond behavior between
}

\section{FRP reinforcing bars and concrete}

\author{
Arnaud Rolland ${ }^{\mathrm{a}, *}$, Pierre Argoul $^{\mathrm{b}}$, Karim Benzartic, Marc Quiertant ${ }^{\mathrm{b}}$, Sylvain \\ Chataigner $^{\text {, }}$, Aghiad Khadour ${ }^{b}$
}

${ }^{\text {a } C e r e m a ~ N o r d-P i c a r d i e, ~} 42$ bis rue Marais, Haubourdin F-59482, France

${ }^{\mathrm{b}}$ Université Paris-Est, MAST, IFSTTAR, 14-20 Bd Newton, F-77447 Marne-la-Vallée, France

${ }^{\mathrm{c}}$ Université Paris-Est, Laboratoire Navier (UMR 8205), IFSTTAR, 14-20 Bd Newton, F-77447

Marne-la-Vallée, France

${ }^{\mathrm{d}}$ IFSTTAR, Route de Bouaye, F-44344 Bouguenais, France

${ }^{*}$ Corresponding author: arnaud.rolland@ cerema.fr (A. Rolland).

\section{Highlights}

- An analytical bond-slip model of the concrete/rebar interface is first proposed

- The identified bond-slip law is then introduced in a finite element (FE) model

- FE model is used to describe the local interface behavior during pull-out tests

- Simulated strain profiles are compared to fiber optic sensor measurements

- Good agreement is found in the interface damage domain at high load level

\section{Keywords}

FRP bars ; Bond ; Analytical \& numerical modeling ; Pull-out tests ; Optical fiber sensors 


\begin{abstract}
This study focuses on the modeling of the local bond behavior of Fiber Reinforced Polymer (FRP) reinforcing bars and the surrounding concrete. An analytical bond-slip model is first proposed to describe the interface behavior of the bars embedded in concrete. Then, the parameters of the bond-slip law are identified from experimental data of pull-out tests performed on specimens instrumented with optical fiber sensors. A specific procedure was developed to identify the model parameters. In a second step, the identified analytical law is introduced in a finite element model (cohesive zone damage model) to simulate the pull-out tests, and a complementary model calibration is proposed to account for the non-uniform stress distribution along the interface. Finally, calculated strain profiles at the bar/concrete interface are compared with the experimental profiles measured by optical fiber sensors. The proposed model is found suitable to simulate the bond mechanisms at high load levels, when there is significant interface damage. However, further development of the model is needed to accurately describe the bond stress and slip response at lower load levels and low/moderate interface damage.
\end{abstract}

\title{
1. Introduction
}

Corrosion of steel reinforcing bars (rebars) is the main cause of degradation of reinforced concrete structures, and has large incidence on maintenance / reparation expenses. To prevent such degradations in new infrastructures, the use of corrosion-free reinforcements, such as Fiber-Reinforced Polymer (FRP) rebars is gaining interest. The main FRP products available on the market are made of glass (GFRP), carbon (CFRP), aramid (AFRP) or basalt (BFRP) fibers, and thermosetting matrices (vinyl ester or epoxy resins). Compared to conventional steel reinforcement, FRP rebars are lighter, stronger in tension, corrosion resistant and electromagnetically neutral (with the exception of CFRP rebars). 
Bond properties between FRP rebars and concrete play a major role in the load transfer process at the local scale, and may also affect mechanical performance of the overall FRP-reinforced concrete structure. The bond behavior depends on many parameters, such as compressive strength of concrete, stiffness of the FRP reinforcement, surface geometry of the rebar, level of adherence between the surface layer (which is usually a sand coating) and the core of the rebar, type of polymer matrix, as well as fiber / matrix interface properties [1-7]. These bond properties can have a strong impact at the structural scale, especially when considering inservice deformations (deflections) and cracking of concrete cover [2].

Up to now, there has been limited use of FRP rebars in construction due to various concerns regarding their long-term durability but also their bond characteristics in concrete. The present paper aims at investigating more specifically these bond characteristics and the mechanism of load transfer between the rebar and surrounding concrete.

Experimental methods commonly used to assess the bond behavior of rebars with concrete are the direct pull-out test and the bond beam test. Described in ACI 440.3R-04 [8], Rilem recommendations [9] and EN 10080 [10], the direct pull-out test is generally considered as the most easy to perform, and was usually adopted in previous studies dedicated to the bond performance of FRP rebars [1-3, 5, 7, 11-15].

As regards theoretical approaches, several analytical models were proposed in the literature to describe the bond-slip behavior of steel or FRP rebars embedded in concrete [12, 16-17]. Numerical modeling based on the finite element method was also conducted to better understand load transfer processes between FRP bars and concrete under specific test configurations [4-6, 18-19].

The present study proposes an original approach for modeling the mechanical behavior of FRP or steel rebars embedded in concrete and subjected to pull-out loading. It relies on previous experimental investigations [20-22], in which pull-out tests were carried out on specimens 
equipped with distributed optical fiber sensors (DOFS). Such an instrumentation made it possible i) to collect continuous strain profiles along the bar/concrete interface, ii) to evaluate the effective development length of selected rebars from the market and iii) to determine the influence of various parameters (characteristics of the sand coating, size of the bar, nature of the fibers) on the bond-slip behavior at the FRP/concrete interface.

In the present research, a first part briefly recalls the outlines of the experimental program (types of bars, geometry of the reinforced concrete (RC) specimens, procedure used for the pull-out tests, DOFS instrumentation) that serves as basis for the present theoretical study. An original approach is then developed to model the bond-slip behavior of RC specimens under pull-out loading configuration:

- an analytical bond-slip law derived from a cohesive zone model is first introduced; its parameters are then identified from experimental data using a specific identification method.

- $\quad$ in a second step, pull-out tests are simulated using Abaqus ${ }^{\circledR}$ Finite Element (FE) code. The interface between the rebar and concrete is modeled using cohesive elements associated with the previously identified analytical bond-slip law.

\section{Outlines of the Experimental Program}

\subsection{Studied rebars}

Various FRP rebars provided by different manufacturers and made of glass, aramid and carbon fibers were used in this study. Corresponding series are identified in the present paper as GLASS, CARBO and ARA respectively. For all these series, main information regarding the manufacturers, commercial brands, nature of fiber and matrix is listed in Table 1, whereas measured tensile properties are reported in Table 2 [20-22]. Rebars of each series were supplied with different surface finishes, either sand coated or plain as shown in Fig. 1. Different studies 
have demonstrated that sand-coating has a strong influence on the bond properties between the bar and the concrete $[\mathbf{1 0}, \mathbf{1 2 - 1 4 , 2 2 ] . ~ I t ~ i s ~ t o ~ n o t e ~ t h a t ~ r e b a r s ~ c o m m e r c i a l i z e d ~ f o r ~ c o n s t r u c t i o n ~}$ applications are systematically produced with a surface relief to improve the bond performance (sand coating, ribs, etc ...). Among the studied products, it should be mentioned that ARA bars are made from braided strands of aramid fibers, which gives them a specific geometry as shown in Fig. 1.

Moreover, various rebar diameters were considered in the experimental campaign for the preparation of the pull-out specimens. Sub-series of specimens are thus labelled xxx-S-yy and xxx-NS-yy, where xxx refers to the series (GLASS, CARBO or ARA), S or NS to the surface finish (sanded and not sanded respectively) and yy to the diameter expressed in mm (Table 3). For the purpose of comparison, ribbed steel rebars of diameter $12 \mathrm{~mm}$ and made of high yield steel (classified as B500B according to EN 10080 standard [10]) were also considered in this this work and are denoted by STEEL-D-12. Their aspect is also depicted in Fig. 1.

Table 1. Types of FRP rebars selected for the test program

\begin{tabular}{llll}
\hline Sample series & $\begin{array}{l}\text { Commercial } \\
\text { brand }\end{array}$ & Manufacturer & Type of fiber / matrix \\
\hline GLASS & V.Rod ${ }^{\circledR}$ & Pultrall ${ }^{\circledR}$, Canada & E-glass / vinyl ester \\
\hline CARBO & Carbopree ${ }^{\circledR}$ & Sireg ${ }^{\circledR}$, Italia & Carbon / vinyl ester \\
\hline ARA & Fibra ${ }^{\circledR}$ & Fibex ${ }^{\circledR}$, Japan & Kevlar 49 $®$ Aramid / epoxy \\
\hline
\end{tabular}




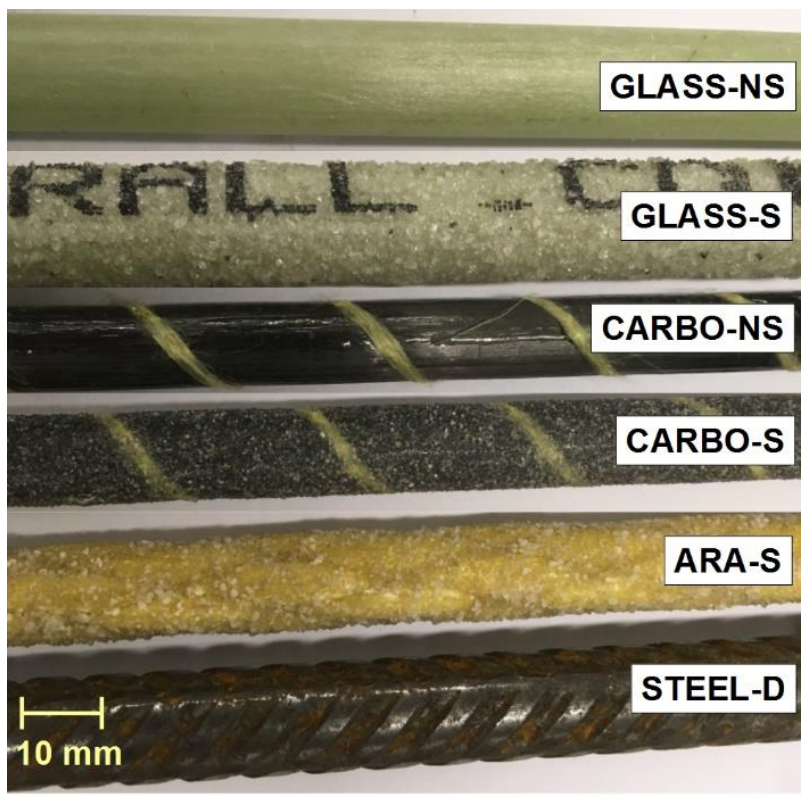

Fig. 1. Surfaces of FRP rebars considered in this study

Table 2. Tensile properties of the FRP bars [22]

\begin{tabular}{lllll}
\hline $\begin{array}{l}\text { Sample } \\
\text { series }\end{array}$ & $\begin{array}{l}\text { Bar } \\
\text { diameter } \\
(\mathbf{m m})\end{array}$ & $\begin{array}{l}\text { Ultimate } \\
\text { load } \\
(\mathbf{k N})\end{array}$ & $\begin{array}{l}\text { Tensile } \\
\text { strength } \\
(\mathbf{M P a})\end{array}$ & $\begin{array}{l}\text { Elastic } \\
\text { modulus } \\
(\mathbf{G P a})\end{array}$ \\
\hline GLASS & 9.5 & $81.0 \pm 3.0$ & $1137 \pm 48$ & $53 \pm 2$ \\
\hline CARBO & 7.5 & $96.0 \pm 9.0$ & $2167 \pm 196$ & $139 \pm 4$ \\
\hline ARA & 5.0 & $36.6 \pm 0.6$ & $1865 \pm 29$ & $80 \pm 3$ \\
\hline
\end{tabular}


Table 3. List of rebars used for preparing pull-out specimens

\begin{tabular}{llll}
\hline Designation & Material & Surface geometry & Diameter (mm) \\
\hline GLASS-S-9.5 & GFRP & Sand-coated & 9.5 \\
\hline GLASS-S-12.7 & GFRP & Sand-coated & 12.7 \\
\hline GLASS-S-15.9 & GFRP & Sand-coated & 15.9 \\
\hline GLASS-NS-12.7 & GFRP & Smooth & 12.7 \\
\hline CARBO-S-10 & CFRP & Sand-coated & 10.0 \\
\hline CARBO-NS-10 & CFRP & Smooth & 10.0 \\
\hline ARA-S-9 & AFRP & Braided / Sand-coated & 9.0 \\
\hline ARA-S-15 & AFRP & Braided / Sand-coated & 15.0 \\
\hline STEEL-D-12 & Deformed steel & Ribbed & 12.0 \\
\hline
\end{tabular}

\subsection{Pull-out tests}

Pull-out tests were performed to assess the bond-slip behavior of the bars embedded in concrete.

Additional details on the experimental program are available in [20-22].

The test setup is shown in Fig. 2. Test specimens consisted of $1.20 \mathrm{~m}$ length bars embedded in concrete cylinders over a length of six times their diameter ( $6 d$ in Fig. 2.b). Three companion concrete cylinders $($ diameter $=16 \mathrm{~cm}$ and length $=32 \mathrm{~cm})$ were cast from the same batch than pull-out samples. After 37 days of cure, compressive tests performed on these cylinders provided an average strength of $28.1 \mathrm{MPa}$ with a standard deviation of $0.4 \mathrm{MPa}$. More details on these compressive tests are available in [20]. 


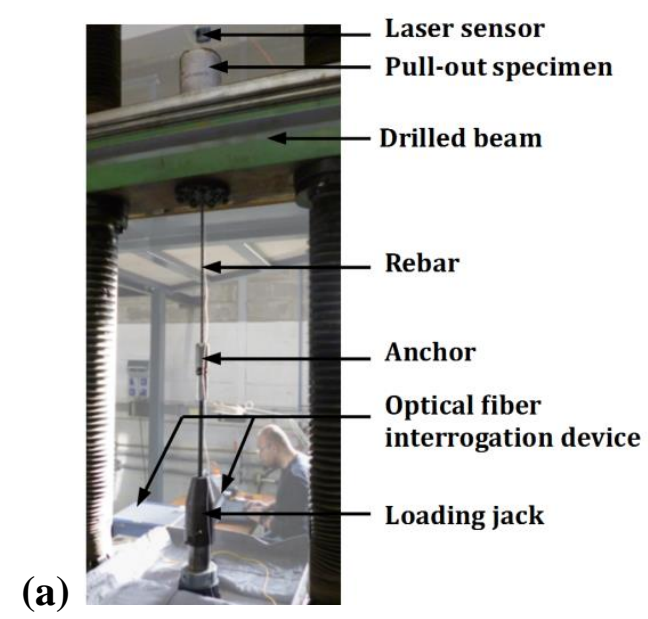

(b)

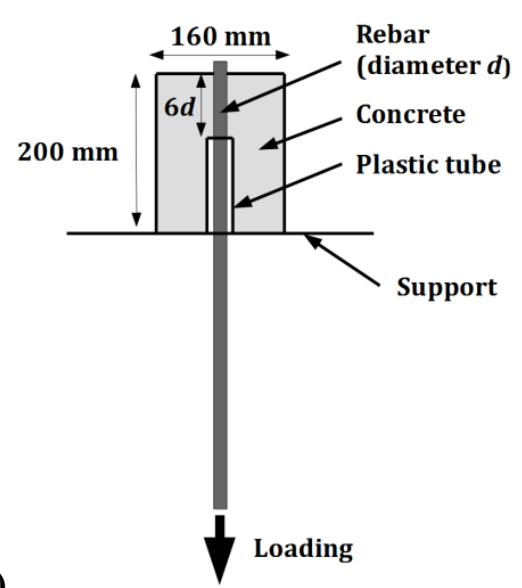

Fig. 2. Description of (a) the pull-out test setup and (b) the specimen geometry

For each sub-series listed in Table 3, two pull-out specimens were tested. Samples of the same sub-series were thus labeled $\mathrm{xxx}-\mathrm{S}-\mathrm{yy}-1$ and $\mathrm{xxx}-\mathrm{S}-\mathrm{yy}-2$. Specimens reinforced by deformed steel rebars were also tested for the sake comparison.

Pull-out tests were performed using a universal testing machine; load was applied to the end of the bar by a hydraulic jack at a speed of $1.2 \mathrm{~mm} / \mathrm{min}$. During the test, the slip of the free end of the bar was measured by a laser sensor, as illustrated in Fig. 2.a. Besides, distributed strain measurements were made at different load levels using optical fibers, in order to determine the strain profiles along the concrete/rebar interface. This instrumentation is detailed in the following section.

\subsection{Optical fiber sensor instrumentation}

Prior to the tests, pull-out specimens were instrumented using Distributed Optical Fiber Sensors (DOFS). This technique allows measuring the strain distribution along the concrete/rebar interface with a high spatial resolution of about $1 \mathrm{~mm}$. Such an instrumentation was successfully used in previous studies related to interface behaviors [23-26]. To enhance bonding of the optical fiber at the surface of the FRP bars, these latter were engraved over a length of $300 \mathrm{~mm}$ and at depth of $2 \mathrm{~mm}$ and the fibers were sealed in the groove using a special glue (Fig. 4). The 
acquisition of the strain profiles along the optical fiber was performed using an Optical Frequency-Domain Reflectometer (OFDR) based on Rayleigh scattering.

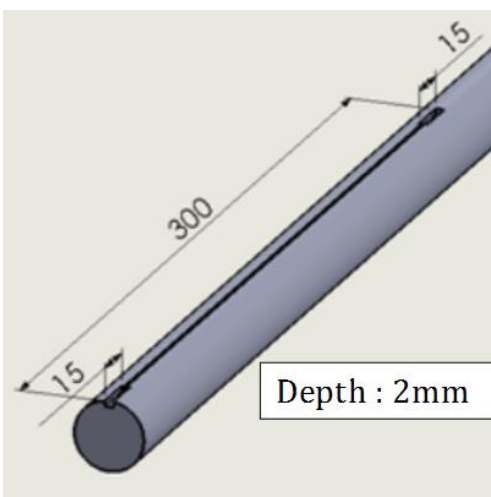

(a)

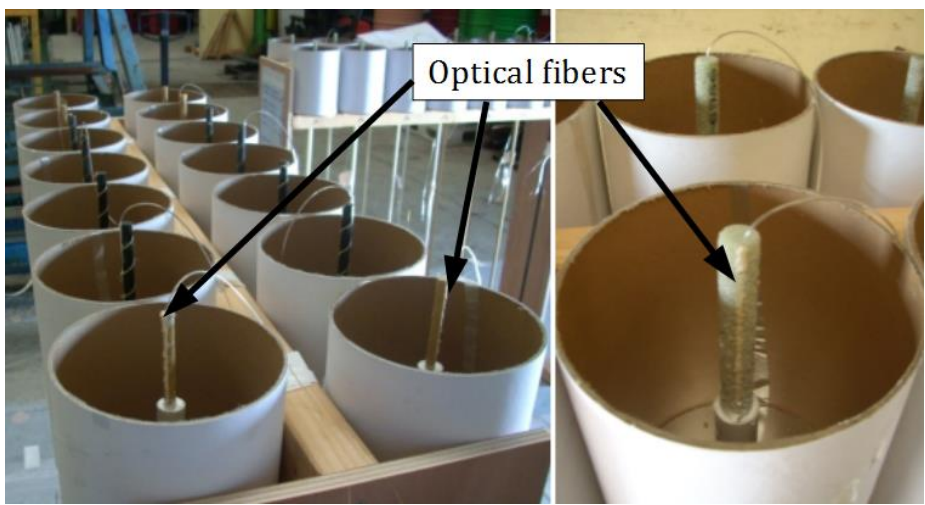

(b)

Fig. 4. (a) Geometry of the groove at the surface of FRP rebars and (b) installation of optical fiber sensors before casting of pull-out specimens

\section{Theoretical description of the bond behavior}

\subsection{Cohesive Zone Model}

In this work, it is proposed to model the bond behavior between the rebar and concrete through a Cohesive Zone Model (CZM). This type of model, originally introduced by Dugdale [27], is dedicated to the description of interfacial phenomena between two surfaces. Constitutive laws associated with CZM models are called traction-separation laws and describe the evolution of the cohesive stress versus the displacement discontinuity, called separation or slip.

The CZM model available in the finite element code Abaqus ${ }^{\circledR}$ was used in this study [28]. The traction-separation law associated with this model is expressed in the general form as follows:

$$
\left\{\begin{array}{l}
t_{n} \\
t_{s} \\
t_{t}
\end{array}\right\}=(1-D)[K]\left[\begin{array}{l}
\delta_{n} \\
\delta_{s} \\
\delta_{t}
\end{array}\right\}
$$


Where $t_{n}, t_{s}$, and $t_{t}$ correspond respectively to the normal stress(es) to separation plane ( $n$ mode: opening), and to the shear stresses in the two different modes ( $s$ mode: off-plan shear, $t$ mode: in-plane shear). $\delta_{n}, \delta_{s}$, and $\delta_{t}$ correspond to the separations (displacements) associated with each corresponding mode. The parameter $D$ is the scalar damage variable (isotropic damage), ranging from 0 (no damage) to 1 (local failure). $[K]$ is the cohesive stiffness tensor.

The matrix form of the behavior law is expressed as:

$$
\left\{\begin{array}{l}
t_{n} \\
t_{s} \\
t_{t}
\end{array}\right\}=(1-D)\left[\begin{array}{lll}
K_{n n} & K_{n s} & K_{n t} \\
K_{n s} & K_{s s} & K_{s t} \\
K_{n t} & K_{s t} & K_{t t}
\end{array}\right]\left\{\begin{array}{l}
\delta_{n} \\
\delta_{s} \\
\delta_{t}
\end{array}\right\}
$$

For the concrete/bar bond behavior, the dominant mode is assumed to be in-plane shear, which leads to consider in the separation vector the value $\delta_{t}$ only, subsequently noted $\delta$. The interface constitutive law can then be written in the following simplified form $\left(t_{t}=\tau, K_{t t}=K_{T}\right)$ :

$$
\tau(\delta)=(1-D) K_{T} \delta
$$

This law is finally governed by two parameters. $K_{T}$ corresponds to the initial stiffness of the shear interface, and $D$ is the scalar damage variable, which can be written as follows:

$$
D(\delta)=1-\frac{\tau(\delta)}{K_{T} \delta}
$$

To simulate as closely as possible the behavior of the bars during a pull-out test, the following paragraphs will focus on developing an analytical bond-slip constitutive law $\tau(\delta)$ adapted to 
describe the bond behavior between the selected bars and concrete. Then, the damage evolution law $D(\delta)$ will be deduced from the proposed analytical law (note that $K_{T}=\left.\frac{d \tau(\delta)}{d \delta}\right|_{(\delta=0)}$ ).

\subsection{Development of an analytical bond-slip model}

Among the bond-slip analytical laws presented in the literature for concrete/bar interfaces, the most frequently cited are BPE (Bertero-Eligehausen-Popov) [16] and CMR (CosenzaManfredi-Realfonzo) [12] models. Corresponding typical bond-slip curves are shown in Fig. 5. These models describe the evolution of the shear stress $\tau$ as a function of the slip of the bar $s$. The response to an increasing monotonic load consists in a first non-linear ascending branch below the ultimate bond stress $\tau_{1}$ at $s=s_{1}$, possibly followed by a horizontal plateau extending up to $s_{2}$ (in the case of BPE model only), then a linear descending branch up to $s_{3}$, and finally a final plateau corresponding to a residual bond-stress $\tau_{3}$ attributed to shear friction.

In the case of BPE model, the analytical expression of the ascending branch $\tau(s)$ is:

$$
\tau(s)=\tau_{1}\left(\frac{s}{s_{1}}\right)^{\alpha}: 0 \leq s \leq s_{1}
$$

Whereas for CMR model, the ascending branch can be expressed as:

$$
\tau(s)=\tau_{1}\left(1-e^{-s / s_{r}}\right)^{\beta}: 0 \leq s \leq s_{1}
$$

$\alpha, \beta$, and $s_{r}$ are constant parameters, generally extracted from experimental curves. 


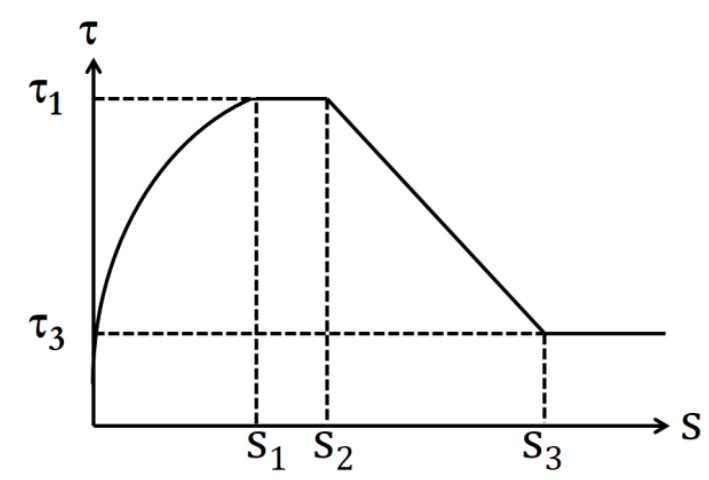

(a)

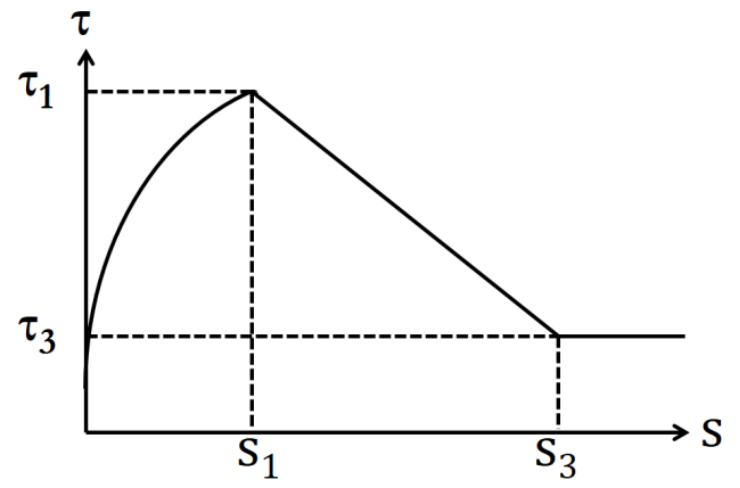

(b)

Fig. 5. Typical bond-slip curves of BPE model (a) and CMR model (b)

These two models both lead to an undefined slope (i.e. infinite slope) at the origin point $(s=0)$, which may create convergence problems or instabilities when implementing the law in a numerical model (infinite initial stiffness $K_{T}$ ). To overcome this difficulty, the following bondslip law is proposed:

$$
\tau(s)=\left\{\begin{array}{cl}
\tau_{0} \frac{s}{s_{0}} & : 0 \leq s \leq s_{1} \\
\tau_{0}+\left(\tau_{1}-\tau_{0}\right)\left(1+\frac{1}{\alpha}\right)\left(1-\frac{1}{1+\alpha\left(\frac{s-s_{0}}{s_{1}-s_{0}}\right)}\right) & : s_{0}<s \leq s_{1} \\
\tau_{\infty}+\left(\tau_{1}-\tau_{\infty}\right)\left(\frac{1}{1+\beta\left(\frac{s-s_{1}}{s_{1}}\right)}\right) & : s>s_{1}
\end{array}\right\}
$$

The bond-slip response associated with this model is shown in Fig. 6. It consists in a first linear ascending branch of finite slope $K_{T}=\tau_{0} / s_{0}$, followed for slip values above $s_{0}$ by a non-linear branch (hyperbolic) reaching $\tau_{1}$ when the slip is equal to $s_{1}$, and finally a third descending branch (also of the hyperbolic type), with a horizontal asymptote tending to $\tau_{\infty}$. The two parameters $\alpha$ and $\beta$ govern the curvatures of the ascending and descending branches, respectively. 
Although the interface behavior may depend on characteristics of the constituent materials (FRP bar and concrete), the present approach is based on a phenomenological model and doesn't include explicit expression for the influence of material properties. As a result, the model parameters are only valid for specimens which served for their identification. In a future generalization of the model to other types of concrete and FRPs, it could be interesting to enrich the model by including parameters related to material characteristics.

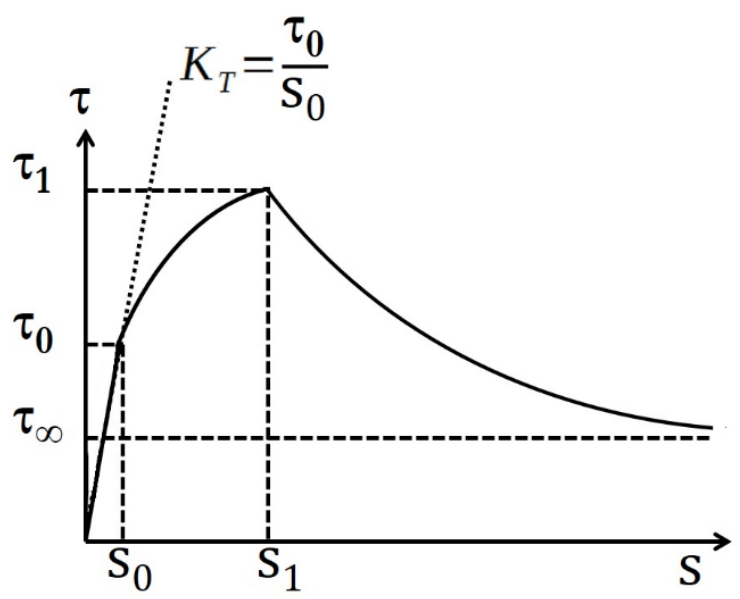

Fig. 6. Bond-slip curve of the proposed analytical model

\section{Identification of the parameters of the bond-slip law}

\subsection{Presentation of the identification method}

The proposed bond stress-slip relationship expressed by Eq. (7) is governed by seven parameters: $s_{0}, \tau_{0}, s_{1}, \tau_{1}, \tau_{\infty}, \alpha$ and $\beta$. To investigate the ability of this model to catch the overall bond behavior of the rebars embedded in concrete, it is necessary to identify the model parameters from experimental data recorded during the pull-out tests.

Considering $n$ couples of values $\left(s_{i}, \tau_{i}\right)$ with $1 \leq i \leq n, n$ being the number of experimental points of each curve, the identification procedure is divided into three steps:

1) The value of $\tau_{l}$ is identified from the experimental curve as the maximum shear stress obtained during the test (i.e. the average bond strength, calculated from the ratio of the 
maximum load to the embedded surface area), and the value of $s_{1}$ is determined by the corresponding slip value.

2) The five other parameters are gathered in a vector $\underline{\theta}=\left[\begin{array}{lll}s_{0} & \tau_{0} & \tau_{\infty} \\ \alpha & \beta\end{array}\right]^{T}$. The optimum value of $\underline{\theta}$ is determined according to the least squares approach by minimizing the following cost function $\Lambda(\underline{\theta})$ :

$$
\Lambda(\underline{\theta})=\sum_{i=1}^{n}\left(\tau_{i}-\tau\left(s_{i}, \underline{\theta}\right)\right)^{2}
$$

3) The minimization is then performed using the Leastsq ${ }^{\circledR}$ algorithm [29] in Scilab® environment, by the iterative Quasi-Newton BFGS (Broyden-Fletcher-GoldfarbShanno) method [30]. The initial values of parameters $s_{0}, \tau_{0}, \tau_{\infty}, \alpha$ and $\beta$ to be optimized are respectively set to $s_{0,0}=s_{1} / 2, \tau_{0,0}=\tau_{\infty, 0}=\tau_{1}$ and $\alpha_{0}=\beta_{0}=1$. The iterations end when the gradient norm of $\Lambda(\theta)$ becomes less than $10^{-6}$.

\subsection{Results of the identification}

The identification procedure of the model parameters was applied to 17 experimental bond-slip curves made of $n \approx 1000$ points per curve (see Fig. 8-12). For each point, the bond stress is calculated at every loading step as the average shear stress, $\tau_{m o y}$, corresponding to the current loading force exerted on the loaded end of the bar, divided by the surface of the bar embedded in concrete:

$$
\tau_{m o y}=\frac{F}{\pi d L}
$$


Results of the identifications are all gathered in Table 4. The graphs plotted in Figs. 8-12 compare the experimental curves (plain lines) recorded during the pull-out tests on specimens reinforced with the various rebars, to the simulations (dotted lines) provided by the model considering the identified sets of parameters.

It should be noted that all specimens tested in the framework of this experimental campaign exhibited pull-out type failure mode (see Fig. 7).

Note also that the experimental slip of ARA-S-9-2 specimen could not be recorded due to a breakdown of the laser sensor, hence no simulation could be achieved for this peculiar test specimen.
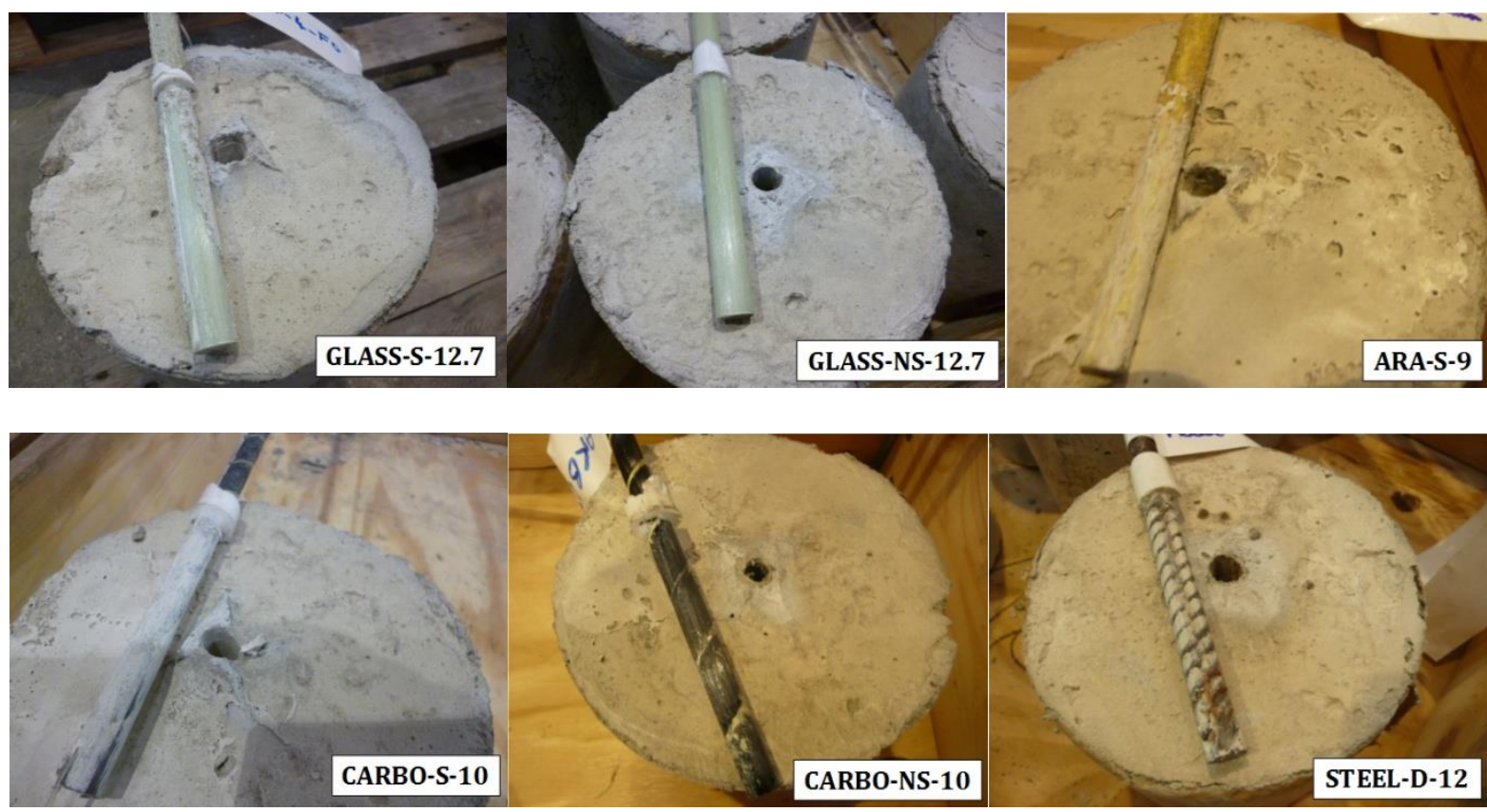

Fig 7. Typical failure modes observed for the various pull-out specimens 
Table 4. Results of the identification procedure for the various pull-out specimens

\begin{tabular}{lllllllll}
\hline Rebar & Sample no. & $\begin{array}{l}s_{0} \\
(\mathbf{m m})\end{array}$ & $\begin{array}{l}\tau_{0} \\
(\mathbf{M P a})\end{array}$ & $\begin{array}{l}S_{1} \\
(\mathbf{m m})\end{array}$ & $\begin{array}{l}\tau_{1} \\
(\mathbf{M P a})\end{array}$ & $\begin{array}{l}\tau_{\infty} \\
(\mathbf{M P a})\end{array}$ & $\alpha$ & $\beta$ \\
\hline GLASS-S-9.5 & 1 & 0.20 & 5.35 & 1.14 & 6.95 & -14.25 & 0.47 & 0.03 \\
\hline GLASS-S-12.7 & 2 & 0.05 & 6.99 & 0.13 & 7.88 & 3.52 & 10.93 & 0.03 \\
\hline & 2 & 0.29 & 6.79 & 1.24 & 9.28 & 3.83 & 2.37 & 0.19 \\
\hline GLASS-S-15.9 & 1 & 0.31 & 6.50 & 1.26 & 11.13 & -0.31 & 3.39 & 0.08 \\
\hline & 2 & 0.31 & 5.10 & 1.53 & 9.70 & 6.85 & 3.43 & 0.63 \\
\hline GLASS-NS-12.7 & 1 & 0.19 & 5.20 & 1.36 & 11.06 & 8.20 & 4.31 & 0.60 \\
\hline & 2 & 0.08 & 0.99 & 2.75 & 1.90 & -17.28 & 27.82 & 0.01 \\
\hline CARBO-S-10 & 1 & 0.12 & 0.77 & 4.75 & 1.88 & -16.62 & 8.76 & 0.02 \\
\hline & 2 & 0.12 & 6.13 & 0.38 & 6.60 & 73.12 & 7.78 & $2.3 \times 10^{-4}$ \\
\hline CARBO-NS-10 & 1 & 0.25 & 5.55 & 7.46 & 7.79 & -2.34 & 0.47 & 0.08 \\
\hline ARA-S-9 & 2 & 0.11 & 2.17 & 3.59 & 7.10 & -46.14 & 3.99 & $9.6 \times 10^{-3}$ \\
\hline & 1 & 0.03 & 1.01 & 6.54 & 5.69 & 3.36 & 12.93 & 0.68 \\
\hline ARA-S15 & 2 & - & - & - & - & - & - & - \\
\hline & 1 & 0.23 & 7.25 & 3.96 & 8.91 & -6.28 & 19.61 & 0.04 \\
\hline STEEL-D-12 & 2 & 0.04 & 4.16 & 8.01 & 7.53 & -27.09 & 13.22 & 0.04 \\
\hline & 1 & 0.05 & 2.91 & 1.50 & 8.21 & -3.23 & 4.25 & 0.15 \\
\hline & 2 & 0.03 & 1.70 & 1.51 & 11.28 & -5.87 & 4.19 & 0.17 \\
\hline
\end{tabular}

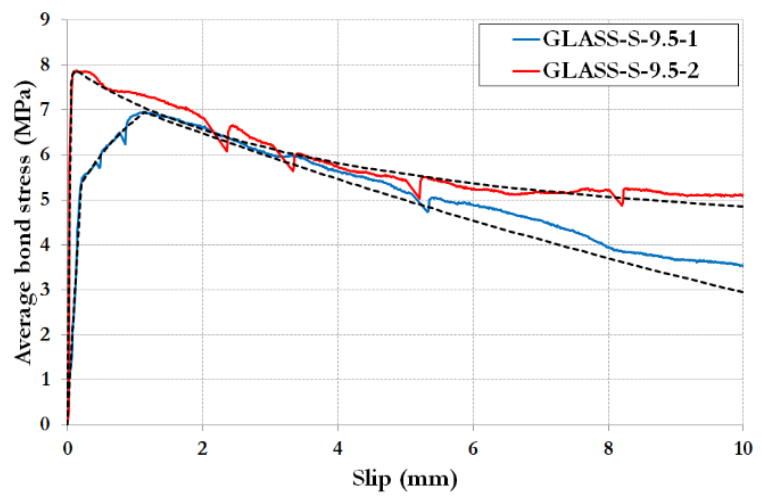

(a)

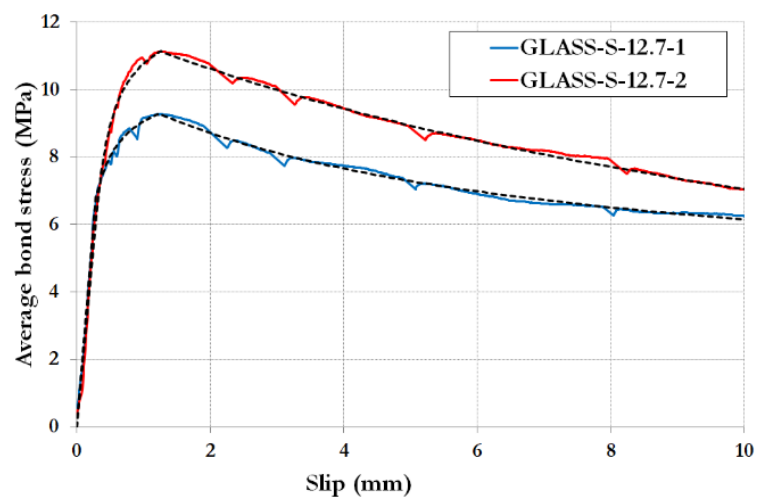

(b)

Fig. 8. Experimental (plain lines) and simulated (dotted lines) bond-slip curves for (a) GLASS-S-9.5 and (b) GLASS-S-12.7 specimens 


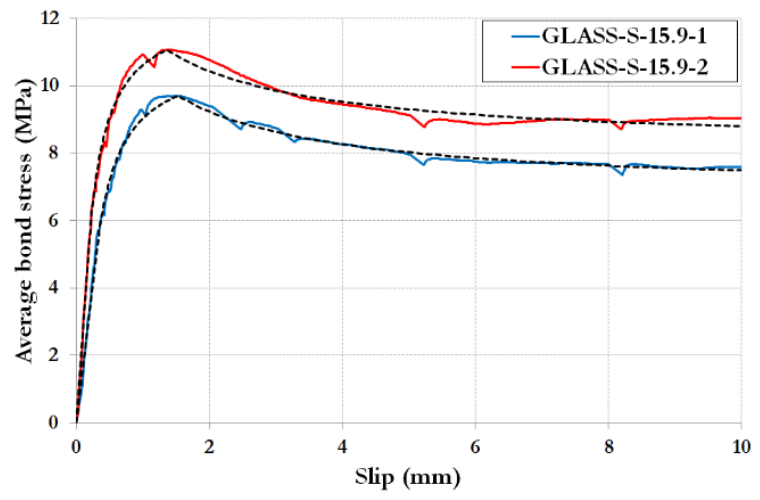

(a)

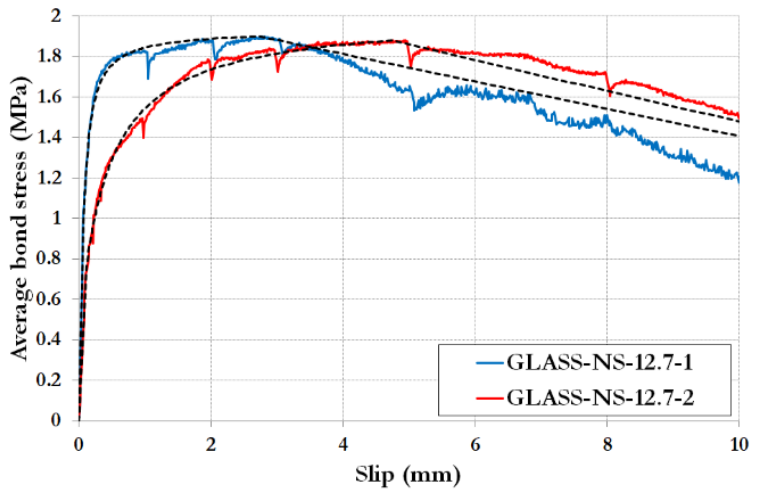

(b)

Fig. 9. Experimental (plain lines) and simulated (dotted lines) bond-slip curves for (a) GLASS-S-15.9 and (b) GLASS-NS-12.7 specimens

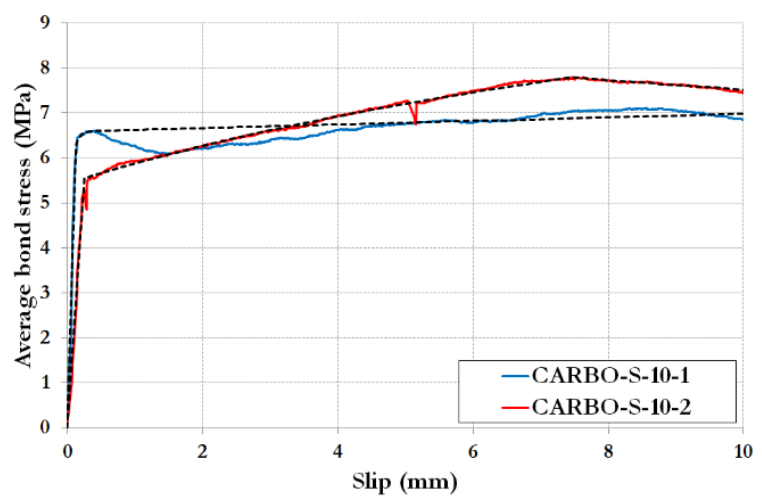

(a)

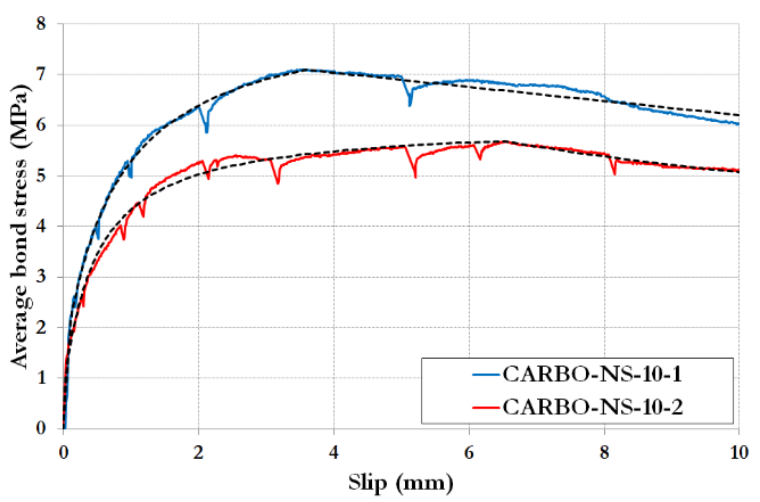

(b)

Fig. 10. Experimental (plain lines) and simulated (dotted lines) bond-slip curves for (a) CARBO-S-10 and (b) CARBO-NS-10 specimens

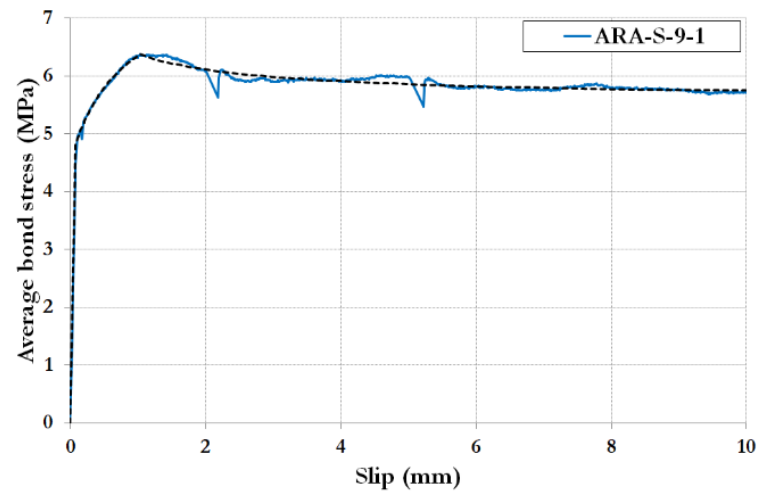

(a)

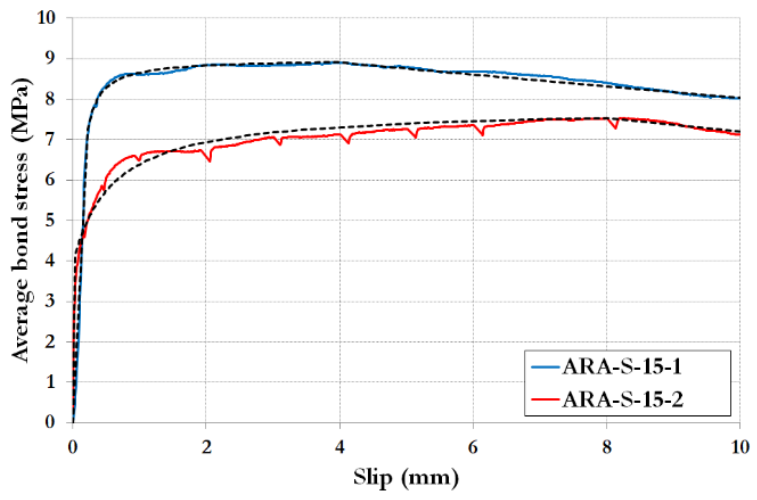

(b)

Fig. 11. Experimental (plain lines) and simulated (dotted lines) bond-slip curves (a) ARA-S-9 and (b) ARA-S-15 specimens 


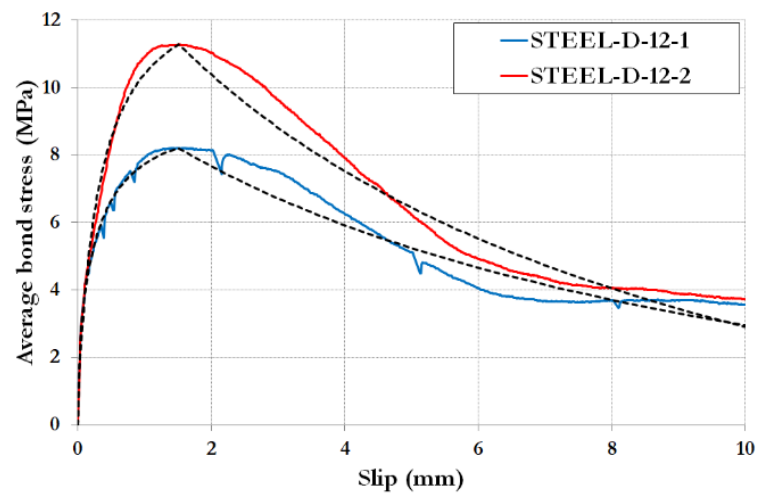

Fig. 12. Experimental (plain lines) and simulated (dotted lines) bond-slip curves for STEELD-12 specimens

Comparison with experimental data show that the model is able to describe satisfactorily the global bond-slip response of the system (based on the average stress and the global slip) whatever the type of bar considered.

Some differences can be noted between specimens of a same series, both for experimental and fitted curves. This may be due to the inhomogeneous nature of concrete which can affect the initial stiffness and strength of the concrete/rebar interface, hence the values of several related parameters of the model. $s_{0}$ and $s_{1}$ are among the most affected parameters.

In order to model the concrete/bar interface behavior more accurately (i.e., at the local scale) and compare theoretical simulations to the continuous strain profiles provided by DOFS, the identified bond-slip laws can now be implemented in the numerical cohesive zone model previously introduced in section 3.1 .

\section{Numerical modeling}

\subsection{Finite element mesh and loading conditions}

Numerical analyses of the pull-out tests were carried out using Abaqus® finite element code. Given the geometry of the problem, a 2D axisymmetric model was adopted in which the rebar is positioned along the axis of symmetry, thus reducing the number of elements of the mesh 
(Fig. 13). Close to the cohesion layer, the size of the mesh elements was refined to accurately describe the deformation and stress gradients, whereas in the other concrete regions, a coarser mesh was used to reduce the computational cost. The concrete and the reinforcement domains were discretized using 4 nodes Continuous AXisymmetric quadrangular elements (CAX4 [28]). A row of COHesive AXisymmetric quadrangular elements with 4 nodes (COHAX4 [28]) was intercalated between the concrete and rebar domains, in order to permit a bond-slip effect.

The loading condition consisted in applying an axial displacement (in the pull-out direction) to the nodes at the upper end of the bar, while the vertical displacement was blocked for the nodes of the concrete block that are in contact with the reaction support. The other faces of the concrete specimen were left free of displacement constraints (see Fig. 13.a).

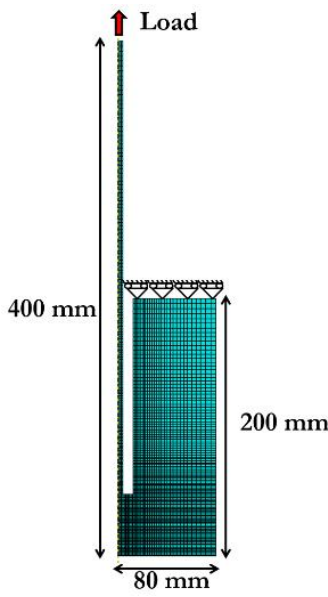

(a)

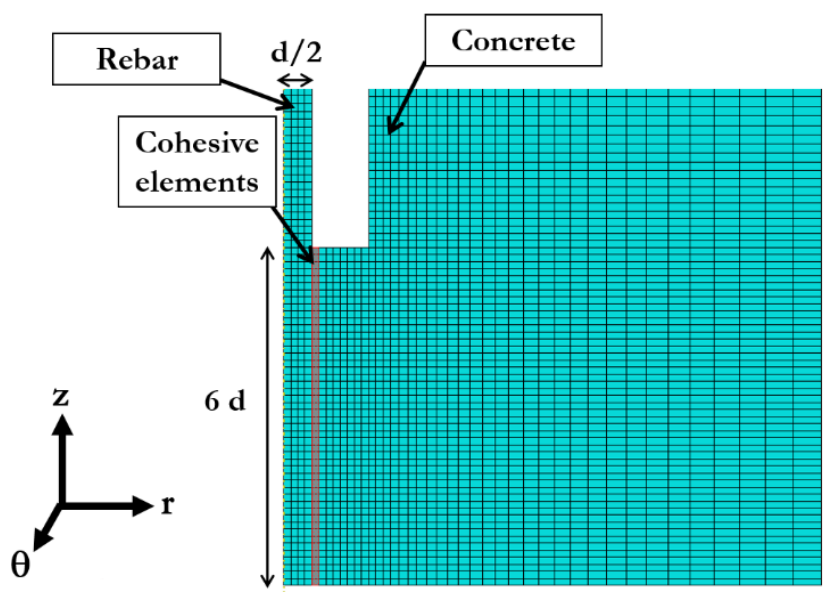

(b)

Fig. 13. Mesh of the model: (a) full mesh and (b) zoom into the concrete/bar interface region

Mechanical behaviors of concrete and steel reinforcement are assumed isotropic linear elastic, while FRP reinforcements exhibit an orthotropic linear elastic behavior expressed as follows: 


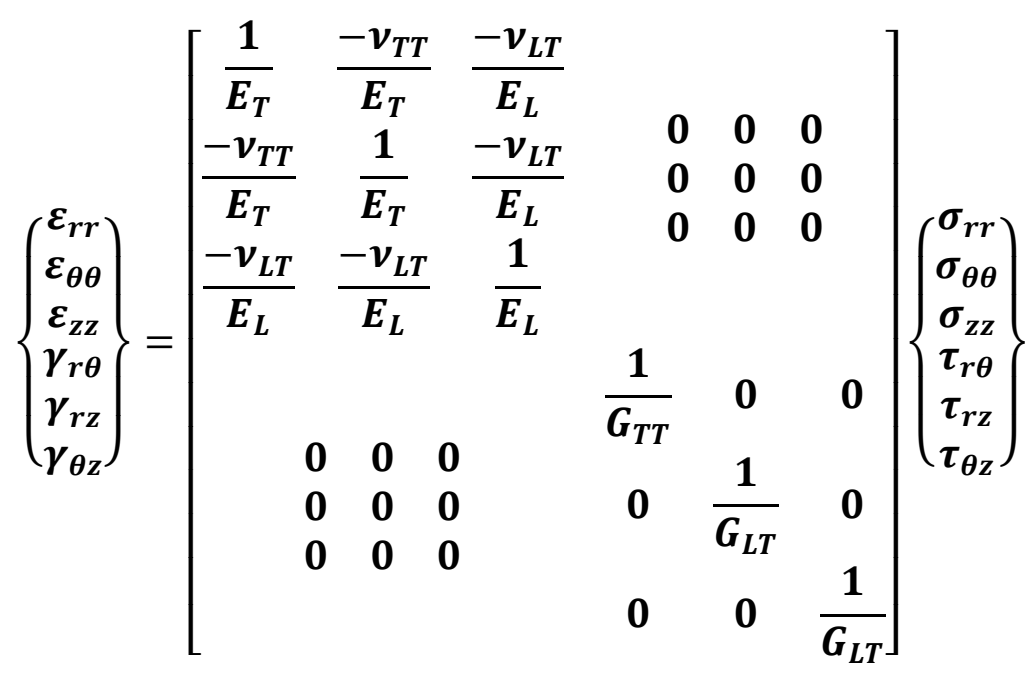

In this expression, $\varepsilon_{i j}$ (resp. $\gamma_{i j}$ ) are the deformation component in traction-compression (resp. in shear), and $\sigma_{i j}$ (reps. $\tau_{i j}$ ) are the corresponding stress component.

The longitudinal moduli of elasticity of the FRP rebars $E_{L}$ were evaluated by tensile tests [20, 22]. The other parameters $E_{T}, G_{L T}, G_{T T}, v_{L T}$ and $v_{T T}$ ( $L$ for the longitudinal direction and $T$ for the transverse direction) were calculated from the properties of the fibers and the polymer matrix, according to usual rules of mixtures [31]:

$$
\left\{\begin{array}{l}
E_{L}=E_{f} V_{f}+E_{m} V_{m} \\
E_{T}=\frac{E_{f} E_{m}}{E_{f} V_{m}+E_{m} V_{f}} \\
G_{L T}=\frac{G_{m} G_{f}}{G_{f} V_{m}+G_{m} V_{f}} \\
v_{L T}=v_{f} V_{f}+v_{m} V_{m} \\
v_{T T}=v_{m} \\
G_{T T}=\frac{E_{T}}{2\left(1+v_{T T}\right)}
\end{array}\right\}
$$


$E_{f}, v_{f}$ and $G_{f}$ are the longitudinal Young's modulus, the Poisson's ratio and the shear modulus of the fibers, and $E_{m}, v_{m}$ and $G_{m}$ are the Young's modulus, the Poisson's ratio and the shear modulus of the matrix. $V_{f}$ and $V_{m}$ are the volume fraction of fibers and matrix, respectively. Values of material's properties that were computed in the model are listed in Table 5.

Table 5. Properties of concrete and rebars used for the numerical modeling

\begin{tabular}{lcrrrrrrrr}
\hline Material & $V_{f}$ & $\begin{array}{c}E_{L} \\
(\mathrm{GPa})\end{array}$ & $\begin{array}{c}E_{f} \\
(\mathrm{GPa})\end{array}$ & $v_{f}$ & $v_{m}$ & $\begin{array}{c}E_{T} \\
(\mathrm{GPa})\end{array}$ & $\begin{array}{c}G_{\mathrm{LT}} \\
(\mathrm{GPa})\end{array}$ & $v_{\mathrm{LT}}$ & $v_{T T}$ \\
\hline GLASS & 0.69 & 51 & 73 & 0.2 & 0.3 & 22 & 8.5 & 0.2 & 0.3 \\
\hline CARBO & 0.57 & 139 & 240 & 0.3 & 0.3 & 12 & 4.5 & 0.3 & 0.3 \\
\hline ARA & 0.66 & 80 & 120 & 0.4 & 0.3 & 7 & 2.6 & 0.4 & 0.3 \\
\hline STEEL & - & 198 & - & - & - & 198 & 76 & 0.3 & 0.3 \\
\hline CONCRETE & - & 34 & - & - & - & 34 & 14.2 & 0.2 & 0.2 \\
\hline
\end{tabular}

In order to implement the analytical bond-slip model previously proposed into the numerical CZM model, the initial stiffness of the shear interface $K_{T}$ (see Eq. (3)) should be set to $K_{T}=\tau_{0} / s_{0}$. Concerning the damage evolution law, $D(\delta)$ can be directly expressed for a monotonic loading by replacing $\tau(\delta)$ in Eq. (4) by the expression proposed in Eq. (7). In each curve, the damage initiation threshold corresponds to the displacement $s_{0}$, obtained for the shear stress $\tau_{0}$. For each calculation involving a particular kind of rebar, the corresponding identified damage evolution law has been introduced in Abaqus ${ }^{\circledR} \mathrm{FE}$ code via a table of values $\left(\delta_{i}, D_{i}\right)$ describing the evolution of $D(\delta)$ (with a minimum step of $0.01 \mathrm{~mm}$ for $\delta$ ). An example of damage evolution curve (deduced from the analytical law obtained from the pull-out test on GLASS-S-12.7-1 specimen) is shown in Fig. 14. 


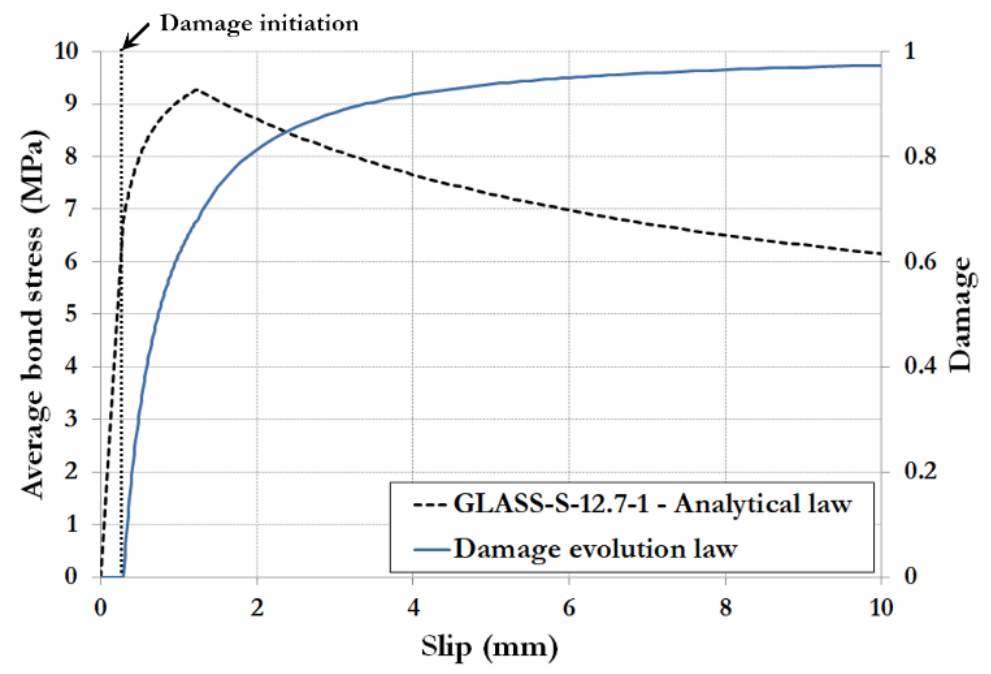

Fig. 14. Example of damage evolution law obtained for specimen GLASS-S-12.7-1

\subsection{FE simulations based on the identified bond-slip laws}

A first series of numerical simulations were performed using the mesh presented in Fig. 13, the elastic parameters reported in Table $\mathbf{5}$ and the analytical bond-slip laws previously identified in section 4.2 for the various bars.

The numerical bond-slip curves (average shear stress versus global slip) are displayed in Fig. 15-19 and compared with results of the analytical calculations. A significant gap is found between the curves provided by the two simulations, although both approaches use the same interface law (i.e the analytical bond-slip model defined in Eq. (7)) to simulate the interface behavior. Such a discrepancy is due to the non-uniform stress distribution along the concrete/bar interface generated by the FE model. Although this condition is more realistic, it is not consistent with the assumption made to identify the parameters of the analytical model that a constant shear stress (equal to the average stress) applies to the entire embedded surface. 


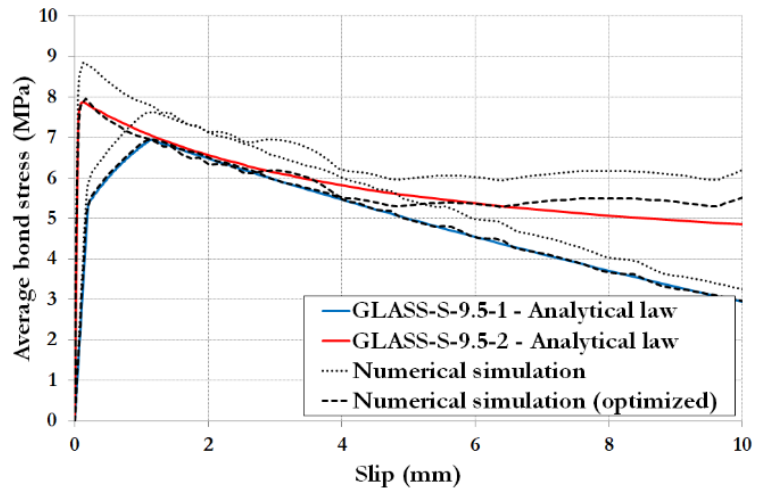

(a)

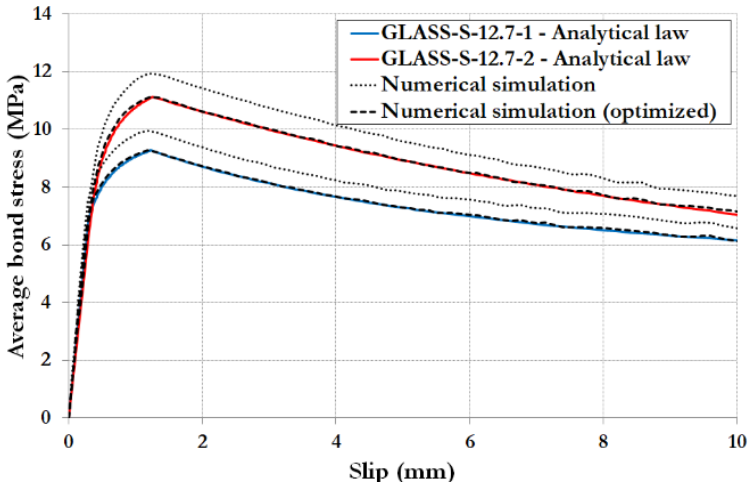

(b)

Fig. 15. Comparison of bond-slip curves provided by the FE model (Numerical simulation) and the analytical model (Analytical law) for (a) GLASS-S-9.5 and (b) GLASS-S-12.7 specimens

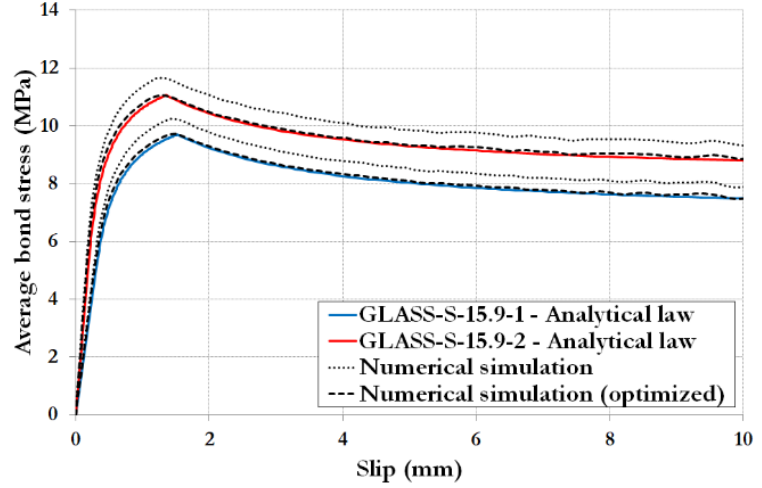

(a)

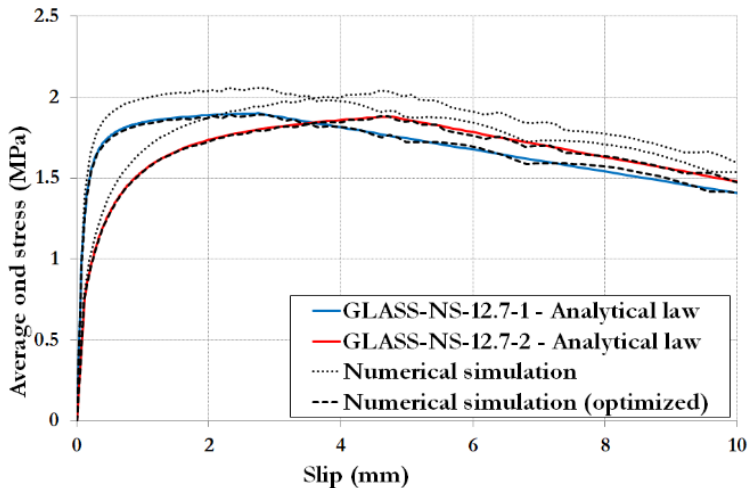

(b)

Fig. 16. Comparison of bond-slip curves provided by the FE model (Numerical simulation) and the analytical model (Analytical law) for (a) GLASS-S-15.9 and (b) GLASS-NS-12.7 specimens 


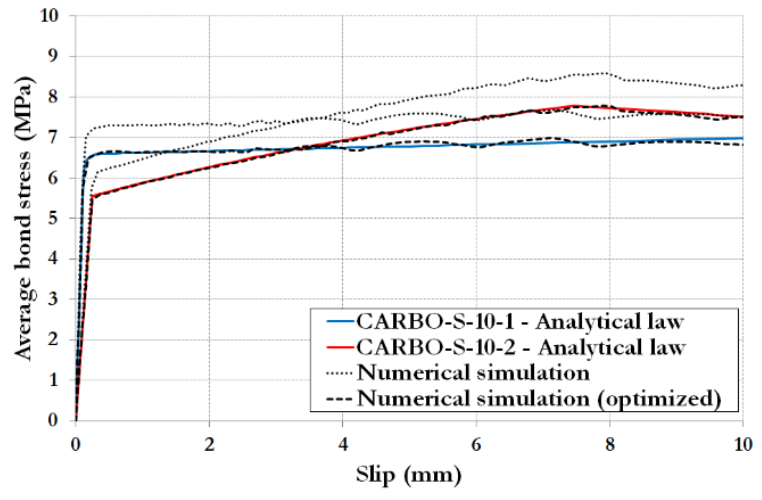

(a)

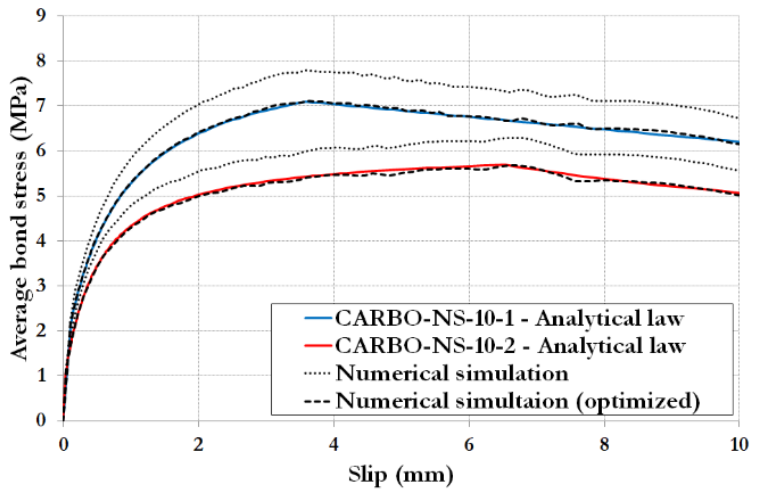

(b)

Fig. 17. Comparison of bond-slip curves provided by the FE model (Numerical simulation) and the analytical model (Analytical law), for (a) CARBO-S-10 and (b) CARBO-NS-10 specimens

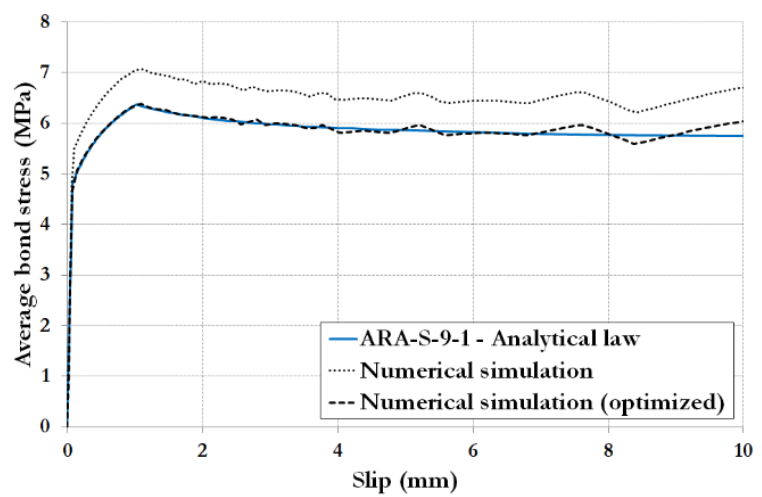

(a)

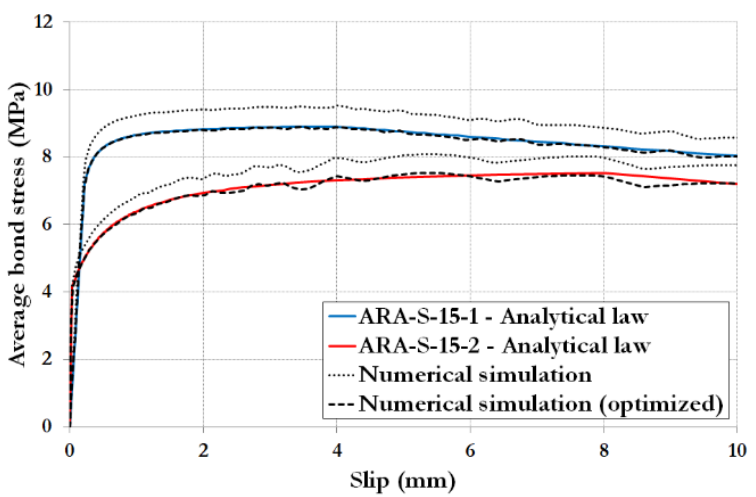

(b)

Fig. 18. Comparison of bond-slip curves provided by the FE model (Numerical simulation) and the analytical model (Analytical law), for (a) ARA-S-9 and (b) ARA-S-15 specimens

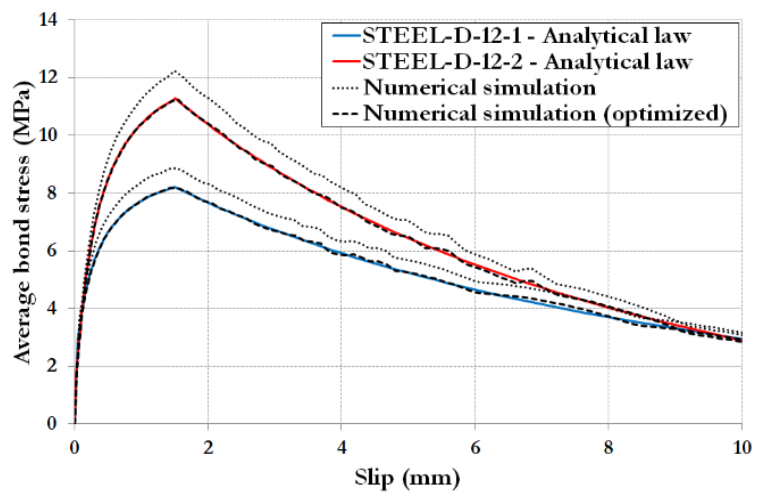

Fig. 19. Comparison of bond-slip curves provided by the FE model (Numerical simulation) and the analytical model (Analytical law) for STEEL-D-12 specimen. 


\subsection{Optimization of the FE calculations}

In the previous sections, the local parameters of the bond-slip law for the cohesive elements were identified from non-local data (average bond stress and slip at the free end of the bar), which resulted in a significant gap between the simulation of the FE model and that of the analytical model (it should be recalled that this latter was identified from experimental data). To improve the response of the FE model, a possible solution is to determine the model parameters by an iterative back-analysis method involving iterative numerical simulations. However, considering that such type procedure remains costly in terms of computing time, a simplified optimization method was preferred, as detailed below.

In order to calibrate the FE model, additional simulation were conducted in Abaqus ${ }^{\circledR}$ taking into account, for the interface elements, a modified analytical law which is expressed by:

$$
\tau^{*}(\delta)=\gamma \tau(\delta)
$$

$\gamma$ is a modulation coefficient equal to the ratio between $\tau_{l}$ (resulting of parameter identification procedure of the analytical model see Table 4) and the maximum bond stress $\tau_{\max , \text { num }}$ raised by the first run of numerical simulations (i.e. results shown in Fig. 15-19). The modulation factor is then calculated as follows:

$$
\gamma=\frac{\tau_{1}}{\tau_{\text {max,num }}}
$$

Values of modulation factors $\gamma$ determined for the various test specimens are reported in Table 6.

Another series of FE numerical simulation was then carried out, in which the interface law was modified by taking into account this modulation factor. Theoretical bond-slip curves provided by this optimized FE model are also displayed in Fig. 15-19 for the various types of specimens, with the label "numerical simulation (optimized)". This time, a good agreement is found 
between the optimized FE simulations and the analytical model, suggesting that the calibration procedure has been successful.

Since different values of experimental strength were generally found for the two specimens of each series (attributed to the heterogeneous nature of concrete), it is to note that significant differences were also provided by numerical simulations.

Table 6. Determination of the modulation coefficient $\gamma$ for the different rebars

\begin{tabular}{llrrr}
\hline \multicolumn{1}{c}{ Bar } & No. & $\tau_{\boldsymbol{I}}(\mathbf{M P a})$ & $\tau_{\text {max } \text { num }}(\mathbf{M P a})$ & \multicolumn{1}{l}{$\gamma$} \\
\hline GLASS-S-9.5 & $\mathbf{1}$ & 6.95 & 7.63 & 0.91 \\
\hline GLASS-S-12.7 & $\mathbf{2}$ & 7.88 & 8.85 & 0.89 \\
\hline GLASS-S-15.9 & $\mathbf{1}$ & 9.28 & 9.97 & 0.93 \\
\hline GLASS-NS-12.7 & $\mathbf{2}$ & 11.13 & 11.95 & 0.93 \\
\hline CARBO-S-10 & $\mathbf{1}$ & 9.70 & 10.23 & 0.95 \\
\hline & $\mathbf{2}$ & 11.06 & 11.67 & 0.95 \\
\hline CARBO-NS-10 & $\mathbf{1}$ & 1.90 & 2.06 & 0.92 \\
\hline & $\mathbf{2}$ & 1.88 & 2.04 & 0.92 \\
\hline ARA-S-9 & $\mathbf{1}$ & 6.60 & 7.26 & 0.91 \\
\hline & $\mathbf{2}$ & 7.79 & 8.59 & 0.91 \\
\hline ARA-S-15 & $\mathbf{1}$ & 5.69 & 7.79 & 0.91 \\
\hline & $\mathbf{2}$ & 6.37 & 6.30 & 0.90 \\
\hline STEEL-D-12 & $\mathbf{1}$ & 8.91 & 7.07 & 0.90 \\
\hline & $\mathbf{2}$ & 7.53 & 9.53 & 0.93 \\
\hline & $\mathbf{1}$ & 8.21 & 8.87 & 0.93 \\
\hline
\end{tabular}

5.3. FE simulation of the interfacial strain profiles and comparison with experimental DOFS measurements 
As the FE model has been calibrated, it can now be used to describe the bond behavior at the local scale, and more particularly, to determine the strain profiles along the concrete/rebar interface.

Figs. 20-26 display the interfacial strain profiles simulated using the optimized FE model (in dashed lines) for the various specimens, and for load levels corresponding approximately to 20 and $80 \%$ of the ultimate bond capacity. In these graphs, the abscissa origin corresponds to the point of the interface located at the end of the embedded section of the rebar (see Fig. 13.b).

For the sake of comparison, interfacial strain profiles collected by the DOFS instrumentation are also plotted on the same graphs. In addition, theoretical strain profiles obtained by considering a perfect bond between the rebar and concrete in the FE calculations (i.e., without cohesive elements at the interface) are also presented in these figures to highlight the role of the cohesive elements in the FE modeling. Note that the strain profiles could not be measured for tests specimens ARA-S-9-2, ARA-S-15-1, CARBO-S-10-1 and STEEL-D-12-2 due to failure of the optical fiber sensors.

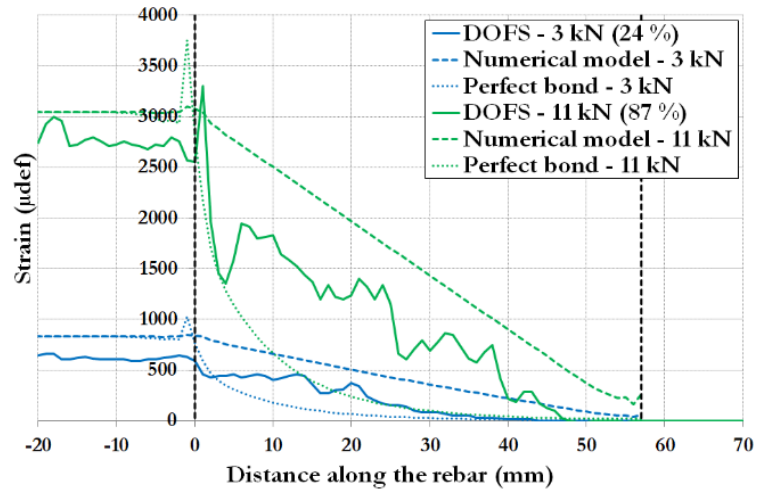

(a)

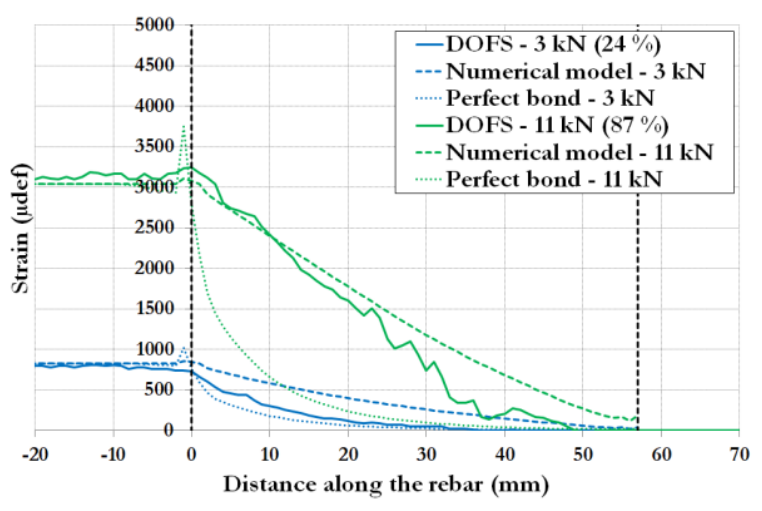

(b)

Fig. 20. Experimental (DOFS) and theoretical strain profiles for (a) GLASS-S-9.5-1 and (b) GLASS-S-9.5-2 specimens 


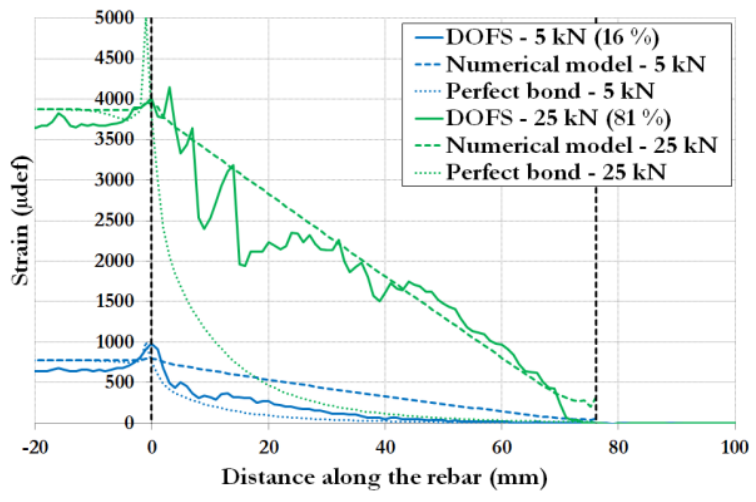

(a)

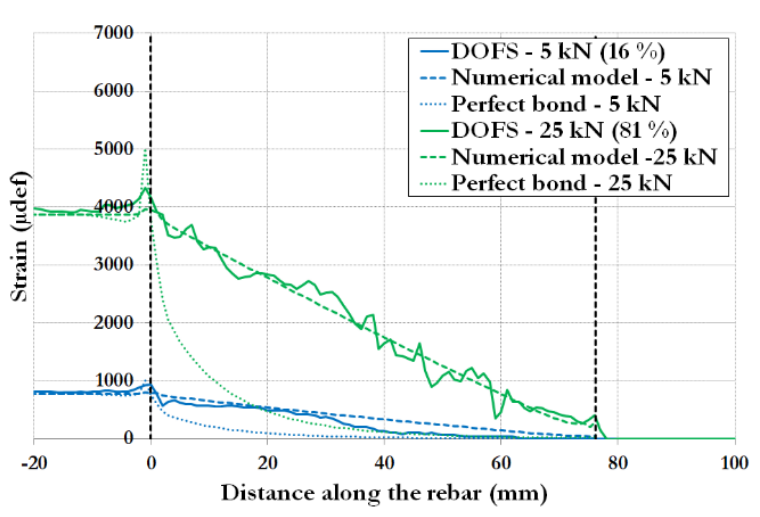

(b)

Fig. 21. Experimental (DOFS) and theoretical strain profiles for (a) GLASS-S-12.7-1 and (b) GLASS-S-12.7-2 specimens

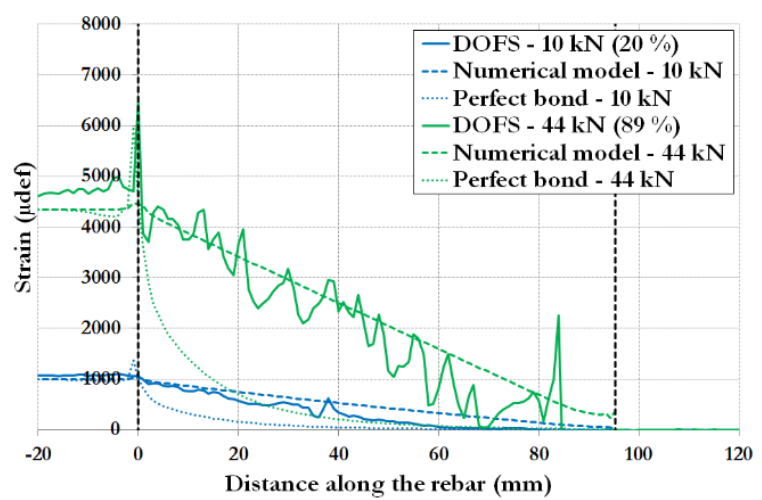

(a)

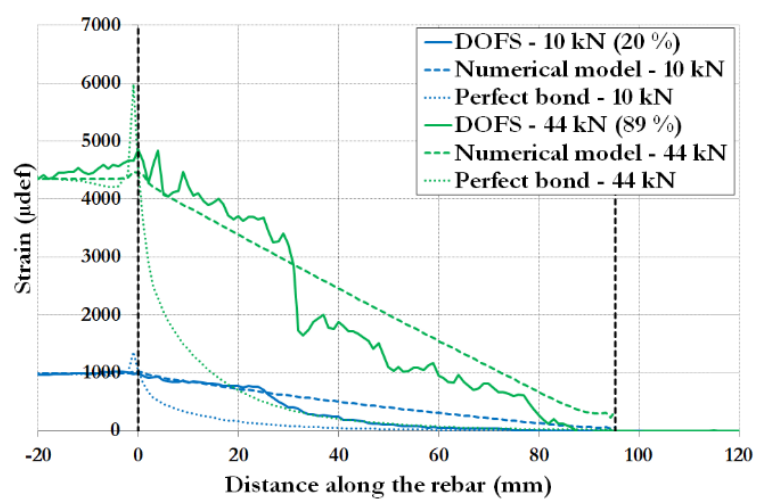

(b)

Fig. 22. Experimental (DOFS) and theoretical strain profiles for (a) GLASS-S-15.9-1 and (b)

GLASS-S-15.9-2 specimens

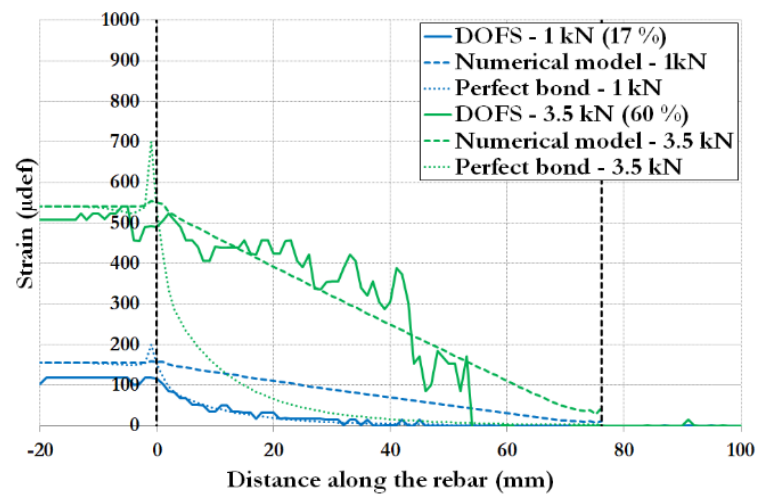

(a)

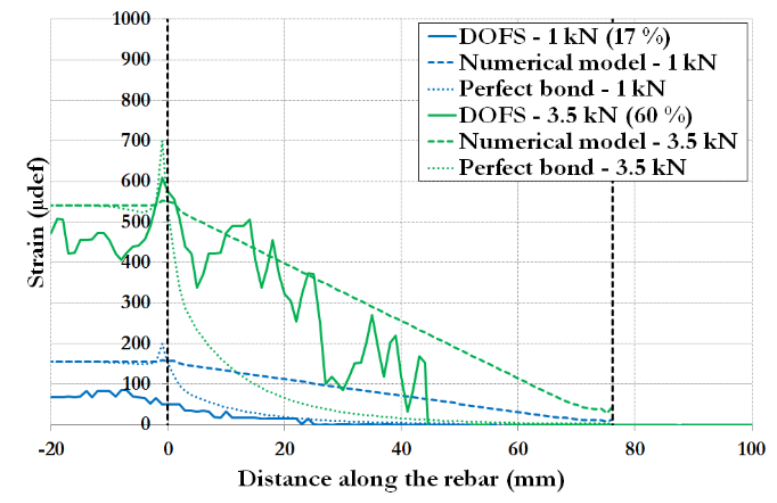

(b)

Fig. 23. Experimental (DOFS) and theoretical strain profiles for (a) GLASS-NS-12.7-1 and (b) GLASS-NS-12.7-2 specimens 


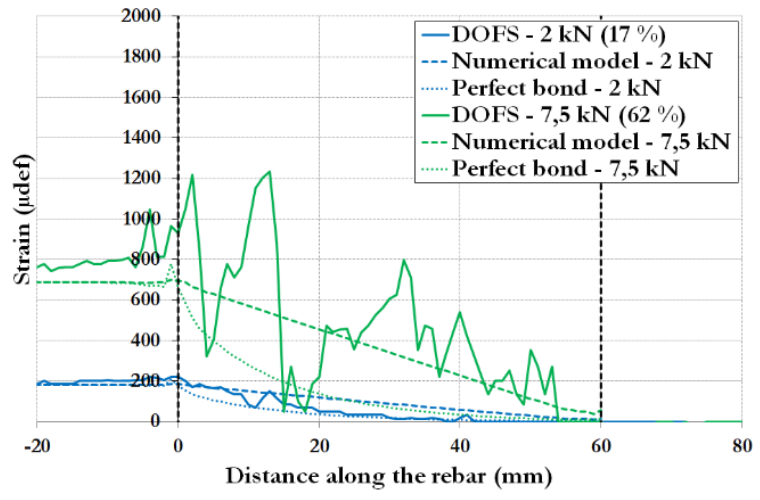

(a)

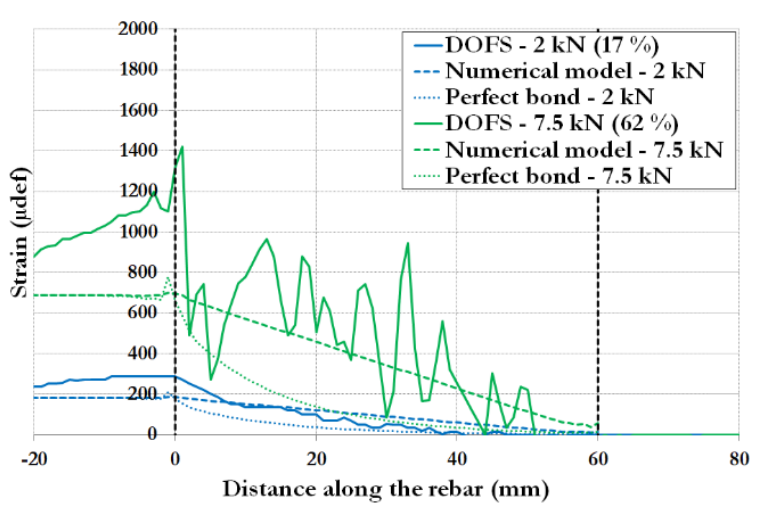

(b)

Fig. 24. Experimental (DOFS) and theoretical strain profiles for (a) CARBO-NS-10-1 and (b) CARBO-NS-10-2 specimens

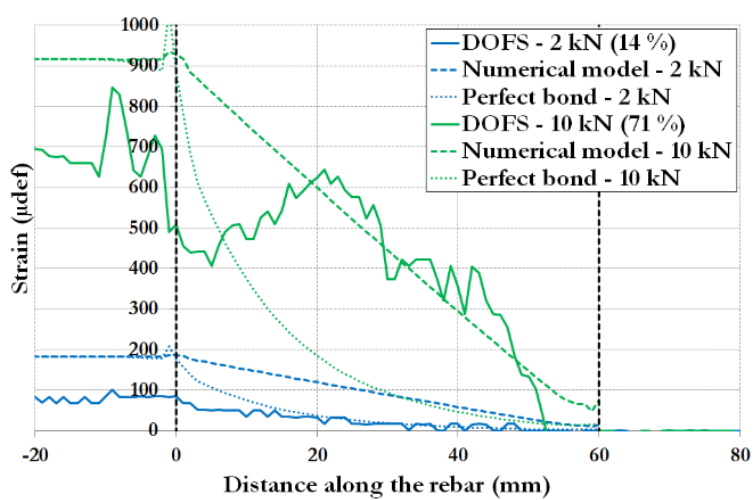

(a)

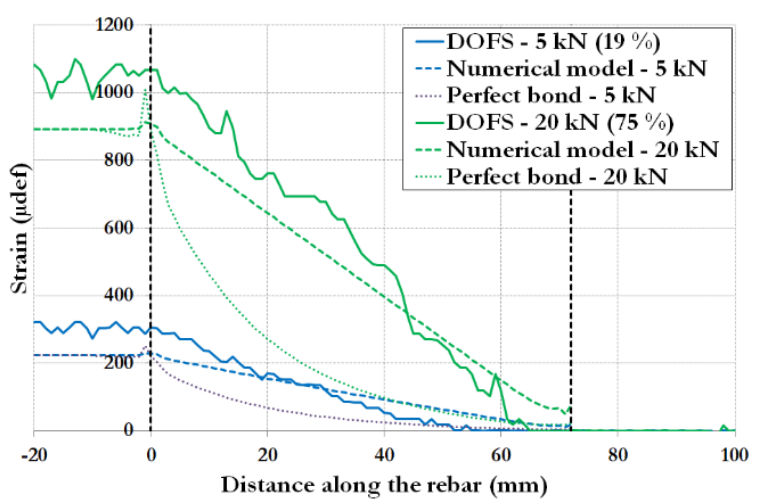

(b)

Fig. 25. Experimental (DOFS) and theoretical strain profiles for (a) CARBO-S-10-2 and (b) STEEL-D-12-1 specimens

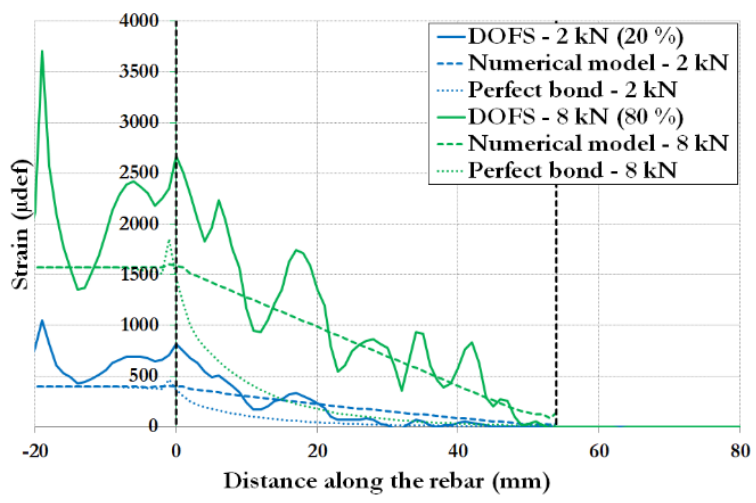

(a)

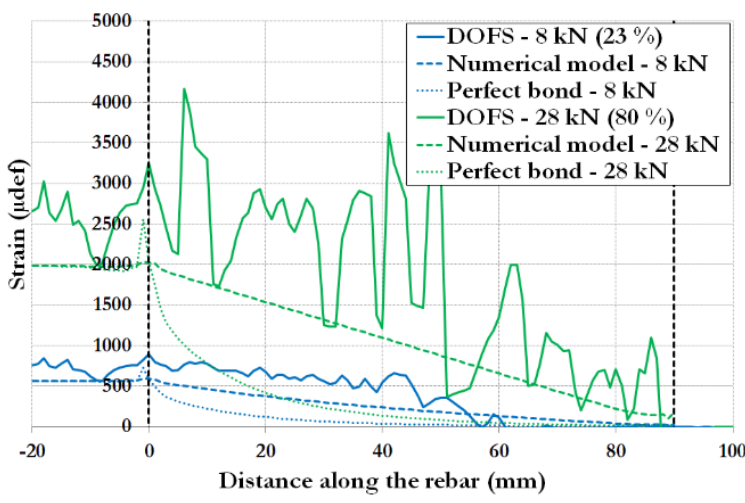

(b)

Fig. 26. Experimental (DOFS) and theoretical strain profiles for (a) ARA-S-9-1 and (b) 
From these curves, it can be noticed that strain profiles obtained from FE simulations using the cohesive elements (curves denoted "Numerical model" in the graphs) exhibit a quasi-linear strain distribution along the embedded length, decreasing from the loaded end to the free end. Differently, FE simulations that consider a perfect bond (curves denoted "Perfect Bond" in the graphs) provide interfacial strain profiles with an exponential shape.

Globally, a good correlation was found between numerical profiles calculated using the cohesive model with optimized parameters and the experimental data for load levels around of $80 \%$ of the ultimate capacity, i.e., when the interface is already significantly damaged. Differently, at lowest load level (around $20 \%$ of the ultimate capacity), experimental strain profiles show a better agreement with the theoretical profiles calculated by considering a perfect interfacial bond, than with simulations from the cohesive zone model.

This result suggests that the initial interface stiffness $\left(K_{T}=\tau_{0} / s_{0}\right)$ considered in the proposed bond-slip model may be too low. Therefore, further development is suited to refine the parameter identification method, and especially the capture of this initial interface stiffness. This parameter may indeed affect significantly the stress distribution at the bar/concrete interface and consequently the development length of the rebars in the FE modeling.

\section{Conclusions}

The objective of this study was to propose a numerical model capable of simulating the bond behavior between FRP rebars and concrete for specimens subjected to pull-out tests. In this context, an analytical bond-slip model based on a variant of the CMR model was first proposed. Although numerous material parameters may actually influence the bond behavior [1-7], an advantage of this phenomenological approach is to describe such behavior with a reduced set of parameters. 
The cohesive law was then identified from experimental data and successfully applied to describe the "global" bond behavior of the specimens during pull-out tests (i.e., the evolution of the average bond stress versus the global slip at the free end of the bar). Since the identification procedure was carried out on each curve of a same series, it made it possible to reproduce each curve, but also the experimental dispersion between samples of the same series. In the case of predictive calculations, an average approach (by averaging the experimental results) would then be necessary.

As the identified bond-slip law had a finite initial slope, it was directly implemented in a FE model (CZM model). A first series of numerical simulations showed significant gap with experimental results, mainly attributed to the fact that parameters of the local bond-slip law of cohesive FE elements are identified from non-local measurements (average shear stress / freeend slip). A simple numerical calibration of the bond-slip law was thus carried-out to optimize the model so that it can describe the non-uniform distribution of the shear stresses at the concrete/bar interface.

Finally, the optimized model made it possible to compute the local strain profiles along the bar / concrete interface. These simulations were then compared with experimental data collected by the DOFS instrumentation at different loading stages, as this innovative technology based on Rayleigh scatter provides continuous strain profiles related to the local interface behavior. In view of the results, the proposed model seems able to simulate the local bond behavior at high load levels, when the interface is significantly damaged. Differently, the comparison shows less agreement at low load levels (i.e., in the case of an undamaged or slightly damage interface) and additional refinement of the model is needed to capture the initial interface stiffness more accurately. Nevertheless, the proposed modeling approach gives promising results and could be extended to other studies. This model is a first step towards the 
development of a robust numerical tool dedicated to the design of FRP reinforced concrete structures.

\section{Acknowledgments}

The authors wish to acknowledge Pultrall®, Sireg ${ }^{\circledR}$ and Fibex ${ }^{\circledR}$ companies for supplying FRP samples used in the experimental program of the present study.

\section{References}

[1] Z. Achillides, P. Pilakoutas, Bond behavior of fiber reinforced polymer bars under direct pullout conditions, Journal of Composites for Construction 2004, 8(2), 173-181.

[2] R. Okelo, R.L. Yuan, Bond strength of fiber reinforced polymer rebars in normal strength concrete, Journal of Composites for Construction 2005, 9(3), 203-213.

[3] G. Maranan, A. Manalo, K. Karunasena, B. Benmokrane. Bond stress-slip behavior: case of GFRP bars in geopolymer concrete, J. Mater. Civ. Eng. 2015, 27 (1), p. 04014116.

[4] G. Fava, V. Carvelli, M. A. Pisani. Remarks on bond of GFRP rebars and concrete, Composites Part B 2016, 93 (1), 210-220.

[5] B. H. Tekle, A. Khennane, O. Kayali. Bond properties of sand-coated bars with fly ashbased geopolymer concrete, J. Compos. Constr. 2016, 20 (5), p. 04016025.

[6] B. H. Tekle, A. Khennane, O. Kayali. Bond behaviour of GFRP reinforcement in alkali activated cement concrete, Construction and Building Materials 2017, 154 (1), 972-982.

[7] T. Li, H. Zhu, Q. Wang, J. Li, T. Wu. Experimental study on the enhancement of additional ribs to the bond performance of FRP bars in concrete, Construction and Building Materials 2018, $185(1), 545-554$. 
[8] ACI 440.3R-04, Guide test methods for fiber-reinforced polymers (FRPs) for reinforcing or strengthening concrete structures”. American Concrete Institute (ACI), Farmington Hills, MI, USA, 2004.

[9] RILEM, RC 6 Bond test for reinforcement steel. 2. Pull-out test”. RILEM Recommendations for the Testing and Use of Construction Materials, 1983, 218-220.

[10] EN 10080 Steel for the reinforcement of concrete - Weldable reinforcing steel - General, European Committee for Standardization (CEN), Brussels, Belgium, 2005.

[11] J. Larralde, R. Silva-Rodriguez, Bond and slip of FRP rebars in concrete, Journal of Materials in Civil Engineering 1993, 5(1), 30-40.

[12] E. Cosenza, G. Manfredi, R. Realfonzo, Behavior and modeling of bond of RFP rebars to concrete, Journal of Composites for Construction 1997, 1(2), 40-51.

[13] L.C. Bank, M. Puterman, A. Katz, The effect of material degradation on bond properties of fiber reinforced plastic reinforcing bars in concrete, ACI Materials Journal 1998, 95(3), 232243.

[14] B. Tighiouart, B. Benmokrane, Investigation on bond in concrete member with fiber reinforced polymer (FRP) bars, Construction and Building Materials 1998, 12(1), 453-462.

[15] M. Robert, B. Benmokrane, Effect of aging on bond of GFRP bars embedded in concrete, Cement and Concrete Composites 2010, 32(1), 461-467.

[16] R. Eligehausen, V. Bertero, E. Popov, Local bond stress-slip relationships of deformed bars under generalized excitations: Tests and analytical model, Report No. 83/23, University of California, Berkeley, California, USA, 1983. https://elib.unistuttgart.de/bitstream/11682/8490/1/eli26.pdf

[17] L.J. Malvar, Bond stress-slip characteristics of FRP rebars, Technical report, Naval Facilities Engineering Service Center, Port Hueneme, Canada, 1994. https://apps.dtic.mil/docs/citations/ADA277191 
[18] N. Newman, A. Ayoub, A. Belarbi, Development length of straight FRP composite bars embedded in concrete, Journal of Reinforced Plastics and Composites 2010, 29(4), 571-589.

[19] H. Mazaheripour, J.A.O. Barros, M. Pepe, A. Giliberti, E. Martinelli, Experimental and theoretical study on bond behavior of GFRP bars in steel fiber reinforced self compacting concrete, Technical report, University of Minho, Guimaraes, Portugal, 2011. https://core.ac.uk/download/pdf/55622062.pdf

[20] A. Rolland, Comportement mécanique et durabilité de structures en béton renforcées par des armatures composites internes, PhD, Université Paris-Est, Ifsttar, France, 2015 (in French). https://tel.archives-ouvertes.fr/tel-01223307

[21] A. Rolland, S. Chataigner, K. Benzarti, M. Quiertant, P. Argoul, J.-M. Paul, Experimental investigation and modelling of the bond between aramid fiber-reinforced polymer bars and concrete, in: Materials and Infrastructures 1, Willey-ISTE, John Wiley and Sons, Inc., Hoboken, New Jersey, 2016,115-128.

[22] A. Rolland, M. Quiertant, A. Khadour, S. Chataigner, K. Benzarti, P. Argoul, Experimental investigations on the bond behavior between concrete and FRP reinforcing bars, Construction and Building Materials 2018, 173(1), 136-148.

[23] M. Quiertant, F. Baby, A. Khadour, P. Marchand, P. Rivillon, J. Billo, R. Lapeyrere, F. Toutlemonde, A. Simon, J. Cordier, J.-C. Renaud, Deformation monitoring of reinforcement bars with a distributed fiber optic sensor for the SHM of reinforced concrete structures, $9^{\text {th }}$ International Conference on NDE in Relation to Structural Integrity for Nuclear and Pressurized Components, Seattle, Washington, USA, 2012.

[24] J.M. Henault, M. Quiertant, S. Delepine-Lesoille, J. Salin, G. Moreau, F. Taillade, K. Benzarti, Quantitative strain measurement and crack detection in RC structures using a truly distributed fiber optic sensing system, Construction and Building Materials 2012, 37, 916-923. 
[25] A. Khadour, F. Baby, A. Herrera, F. Taillade, P. Marchand, P. Rivillon, A. Simon, M. Quiertant, F. Toutlemonde, Distributed strain monitoring of reinforcement bars using optical fibers for SHM, CONSEC13 - Seventh International Conference on Concrete under Severe Conditions - Environment and Loading, Nanjing, China, 2013.

[26] P. Marchand, F. Baby, A. Khadour, T. Battesti, P. Rivillon, M. Quiertant, H.-H. Nguyen, G. Généreux, J.-P. Deveaud, A. Simon, F. Toutlemonde, Bond behaviour of reinforcing bars in UHPFRC, Materials and Structures 2016, 49 (5), 1979-1995.

[27] D.S. Dugdale, Yielding of steel sheets containing slits, Journal of the Mechanics and Physics of Solids 1960, 8(2), 100-104.

[28] Abaqus (2011). Abaqus 6.1 Analysis User's Manual. Simulia.

[29] Scilab Online Help. https://help.scilab.org/docs/6.0.2/en_US/leastsq.html

[30] C.G., Broyden, The convergence of a class of double-rank minimization algorithms, Journal of the Mathematics and its Applications 1970, 6(1), 76-90.

[31] D. Gay, Matériaux Composites, Hermès Editions, Paris, France, 1987. 